Review

\title{
Functional lithium borate salts and their potential application in high performance lithium batteries
}

\author{
Zhihong Liu ${ }^{\mathrm{a}, 1}$, Jingchao Chai ${ }^{\mathrm{a}, \mathrm{b}, 1}$, Gaojie Xua ${ }^{\mathrm{a}}$, Qingfu Wang ${ }^{\mathrm{a}}$, Guanglei Cui ${ }^{\mathrm{a}, *}$ \\ a Qingdao Institute of Bioenergy and Bioprocess Technology, Chinese Academy of Sciences, No. 189 Songling Road, 266101 Qingdao, China \\ ${ }^{\mathrm{b}}$ University of Chinese Academy of Sciences, No. 19A Yuquan Road, 100049 Beijing, China
}

\section{Contents}

1. Introduction .....

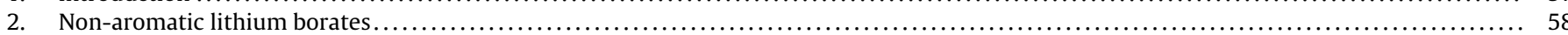

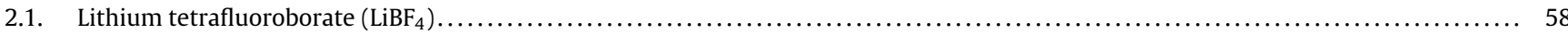

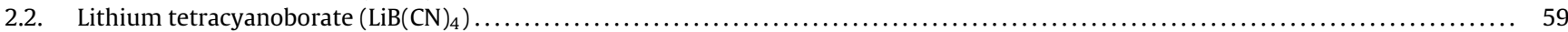

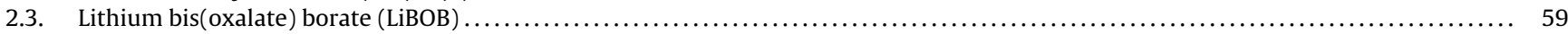

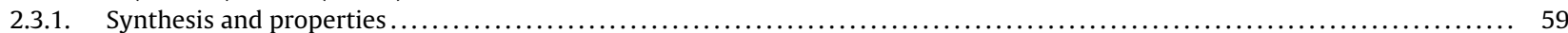

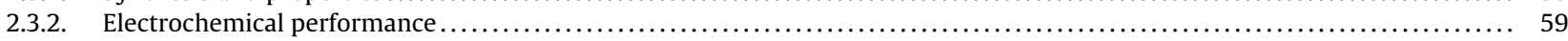

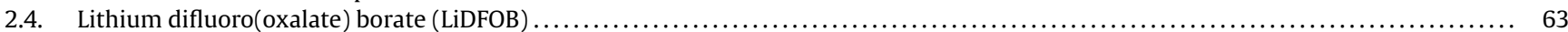

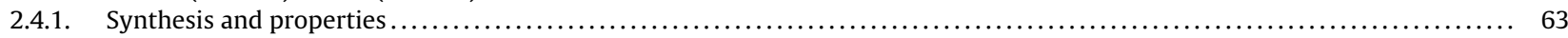

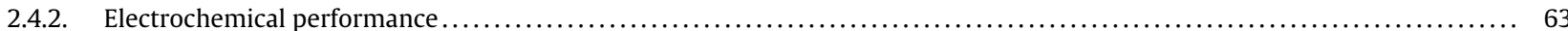

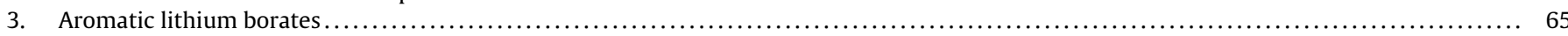

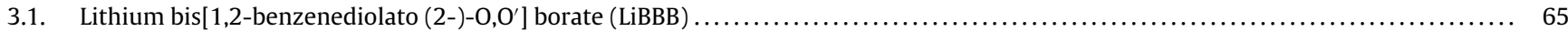

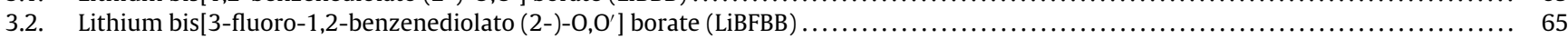

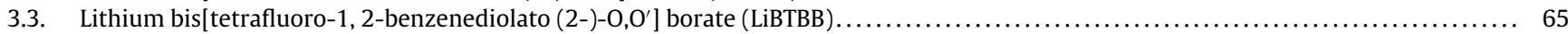

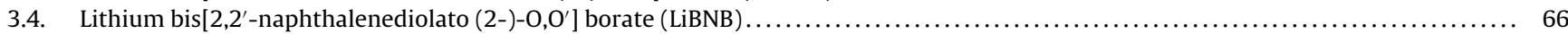

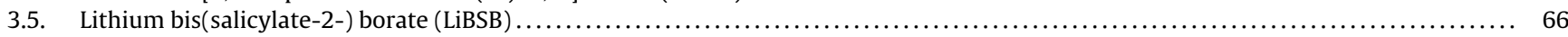

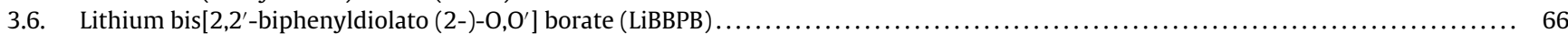

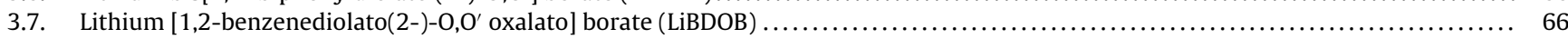

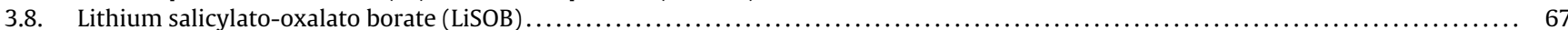

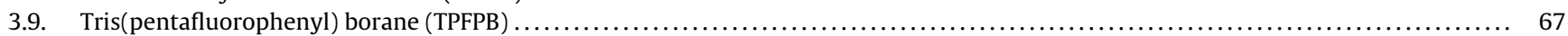

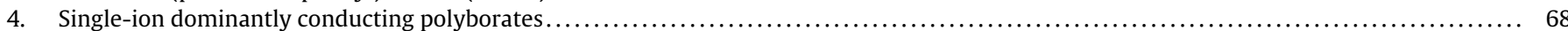

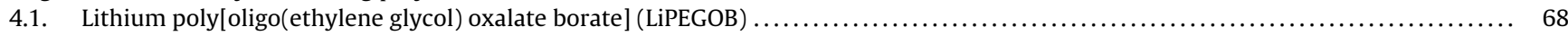

4.2. Lithium polyvinyl alcohol oxalate borate (LiPVAOB) and lithium polyacrylic acid oxalate borate (LiPAAOB) $\ldots \ldots \ldots \ldots \ldots \ldots \ldots \ldots \ldots \ldots . \ldots \ldots$

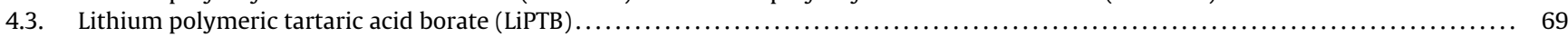

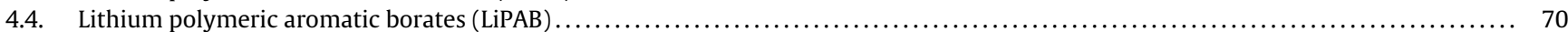

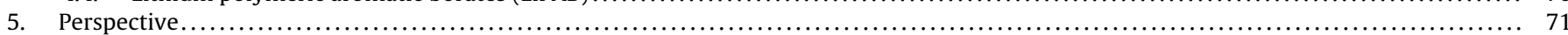

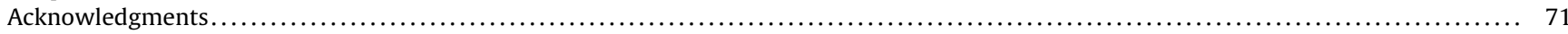

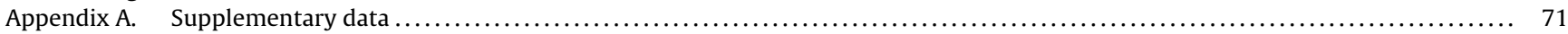

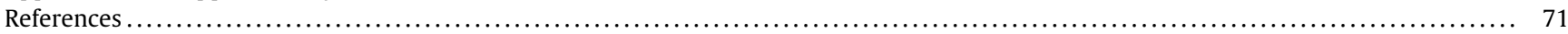

\section{A R T I C L E I N F O}

\section{Article history:}

Received 20 November 2014

Accepted 12 February 2015

Available online 19 February 2015

\begin{abstract}
A B S T R A C T
Lithium borate salts have been arousing intensive interest due to their unique properties such as excellent thermal stability, comparable ionic conductivity, cost-effectiveness, environmental benignity and favorable solid electrolyte interface forming property. Herein, the recent progress of many lithium borate salts and their potential application in high performance lithium batteries using the $\mathrm{Si} / \mathrm{C}$ composite anode, lithium metal anode, high voltage cathodes or semi-solid lithium flowable electrodes are reviewed in regard to their synthesis, properties and battery performance. This review also presents the current progress of single-ion conducting polymeric lithium borate salts, which exhibit high lithium ion
\end{abstract}

\footnotetext{
* Corresponding author. Tel.: +86 532 80662746; fax: +8653280662744.

E-mail address: cuigl@qibebt.ac.cn (G. Cui).

1 These authors contributed equally to this work.
} 
Keywords:

Review

Lithium borate salts

Lithium ion battery

Polymeric electrolyte

Single-ion conductor transference numbers approaching unit. These single-ion dominantly conducting polymeric electrolytes are very desirable in lithium batteries with less polarization since the electrodes only exchange lithium ions with electrolytes. We hope that the new and established researchers in the battery area can obtain a clear perspective of this field and our review can provide the motivation for new attempts in this promising field.

(C) 2015 Elsevier B.V. All rights reserved.

\section{Introduction}

Lithium ion batteries have attracted extensive interest in recent years owing to their ever-increasing application in energy storage systems such as electric vehicles and smart grids. To be aimed at this application, high energy density batteries with low cost and high performance as well as safety are highly desirable. Although lithium- $\mathrm{O}_{2}$ batteries are reported to possess higher energy density more than $600 \mathrm{Wh} \mathrm{kg}^{-1}$, there are still some severe obstacles to overcome before commercialization. As a compromise, the batteries with the $\mathrm{Si} / \mathrm{C}$ composite anode, lithium metal anode, high voltage cathodes or semi-solid lithium flowable electrodes are demonstrated to provide a medium energy density of around $300 \mathrm{Wh} \mathrm{kg}^{-1}$ in the near future [1-6]. In these higher density lithium batteries, the electrolytes play a significant role $[4,5,7]$, impacting not only the power and cycling performance but also the capacity and safety [8,9]. As shown in Fig. 1 the electrolytes serve as the medium for charge transfer of ions between cathode and anode. A generalized list of these requirements for electrolyte should include the following. (i) It should be a good ionic conductor and electronic insulator, so that ion transport can be facile and self-discharge can be kept to a minimum. (ii) It should have wide electrochemical stability, so that electrolyte would not continuously degrade or decompose within the range of the working potentials of both the cathode and the anode. (iii) It should not be corrosive to other cell components such as separators, current collectors and cell packaging materials. (iv) It should be robust against various abuses, such as electrical, mechanical, or thermal conditions. (v) Its components should be cost-effective and environmentally friendly, especially for a large-scale application [5].

The commercialized electrolytes for lithium ion batteries (LIBs) are generally composed of lithium salts dissolved in a solvent [10-20]. $\mathrm{LiPF}_{6}$ is the most widely used lithium salt and propylene carbonate (PC), ethylene carbonate (EC), ethyl methyl carbonate (EMC), diethyl carbonate (DEC), dimethyl carbonate (DMC), or their

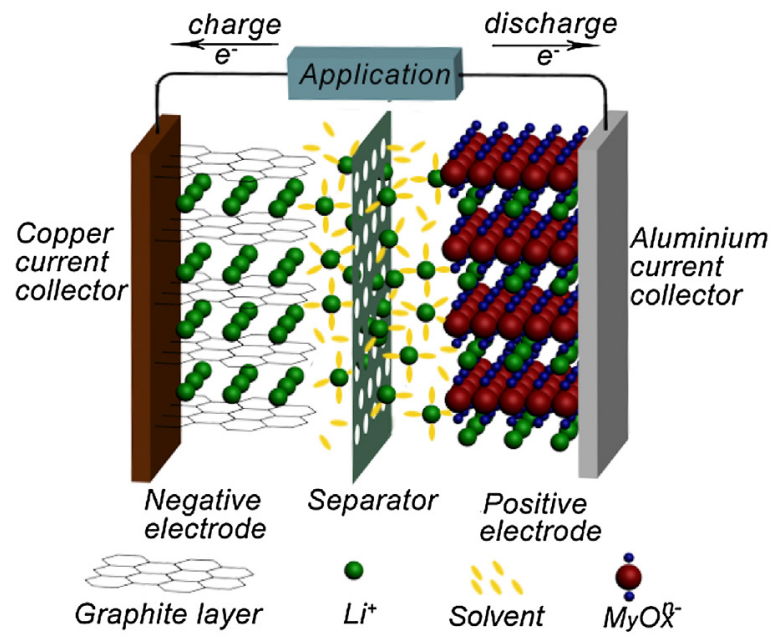

Fig. 1. The operating principle of lithium ion batteries. mixed solvents are the commonly used solvents [21,22]. The cyclic carbonates enable the dissolution of salts to sufficient concentrations because of their high dielectric constant, but they are rather viscous. The linear carbonates, on the other hand, promote rapid ion transport, because of their low viscosity, but their dielectric constant is low [21]. So the mixed solvents consisting of cyclic carbonates and linear carbonates display moderate dielectric constant and low viscosity, which are beneficial for improvement of the ion conductivity and then enhancement of the low temperature performance and rate performance of the batteries.

Even though the commercial salt $\mathrm{LiPF}_{6}$ is successful in portable lithium ion batteries, $\mathrm{LiPF}_{6}$ still has some limitations, which restrict its applications at the elevated temperatures above $50^{\circ} \mathrm{C}[23,24]$. $\mathrm{LiPF}_{6}$ is liable to thermally decompose and very sensitive to moisture $[23,25,26]$, which are depicted in Eqs. (1)-(3). The generated $\mathrm{PF}_{5}$ resulting from thermal decomposition is a very strong Lewis acid, and can react irreversibly with trace of water to generate HF. $\mathrm{HF}$ itself reacts with organics on anode surface to form $\mathrm{LiF}$, which increases the resistance of interphase (SEI) layer. To make matters worse, HF can erode cathode material dissolving metallic ions into the electrolyte and eventually depositing on the anode material surface destabilizing the SEI layers especially at elevated temperatures. The precipitated $\mathrm{LiF}$ from the decomposition of $\mathrm{LiPF}_{6}$ forming a dense coating is the most likely major contributor to the insulating layer found on cycled electrodes $[27,28]$.

$$
\begin{aligned}
& \mathrm{LiPF}_{6} \text { (sol.) } \stackrel{\Delta}{\longrightarrow} \mathrm{LiF}(\text { s })+\mathrm{PF}_{5} \text { (sol.) } \\
& \mathrm{LiPF}_{6} \text { (sol.) }+\mathrm{H}_{2} \mathrm{O} \rightarrow \mathrm{POF}_{3} \text { (sol.) }+\mathrm{LiF}(\mathrm{s})+2 \mathrm{HF}(\text { sol. }) \\
& \mathrm{PF}_{5} \text { (sol.) }+\mathrm{H}_{2} \mathrm{O} \rightarrow \mathrm{POF}_{3} \text { (sol.) }+2 \mathrm{HF} \text { (sol.) }
\end{aligned}
$$

Furthermore, lithium perchlorate $\left(\mathrm{LiClO}_{4}\right)$, lithium hexafluoroarsenate $\left(\mathrm{LiAsF}_{6}\right)$, lithium bis(trifluoromethanesulfonyl)imide (LiTFSI), lithium trifluoromethane-sulfonate (LiTf) and lithium bis(fluorosulfonyl)imide (LiFSI) can also be used as lithium salts, and they all have some merits and demerits [8,29-33]. $\mathrm{LiClO}_{4}$ is one of the earliest salts used in the batteries. The electrolyte composed of $\mathrm{LiClO}_{4}$ presents high conductivity and good thermal stability, but chlorine in $\mathrm{LiClO}_{4}$ is in its highest valence state, strongly oxidizing. $\mathrm{LiClO}_{4}$ can react strongly with organic solvent under extreme conditions (such as at elevated temperature or high charging/discharging current density). Like $\mathrm{LiClO}_{4}, \mathrm{LiAsF}_{6}$ also has a good thermal stability. The electrolyte consisted of $\mathrm{LiAsF}_{6}$ and ether solvent has quite high conductivity. However, the reduction reaction of $\mathrm{LiAsF}_{6}$ will produce arsenic, which is highly poisonous and carcinogenic. Lithium bis(trifluoromethanesulfonyl)imide(LiTFSI), lithium trifluoromethanesulfonate (LiTf) and lithium bis(fluorosulfonyl)imide (LiFSI) possess high thermal stability but corrode the current collector aluminum foil at higher potentials (>3.6 V vs. $\left.\mathrm{Li} / \mathrm{Li}^{+}\right)$[5]. Thus, the search for an alternative salt for lithium batteries is necessary to maintain comprehensive and excellent performance.

Boron is a unique and exciting element. Over the years it has proved a constant challenge and stimulus not only to theoreticians, but also to industrial chemists and technologists. It is the only non-metal in Group IIIA of the periodic table and shows many 


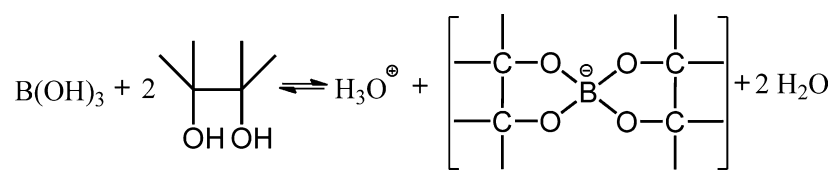

Scheme 1. Schematic illustration of boric acid chelated with polyhydric alcohols.

similarities to its neighbor, carbon, and its diagonal relative, silicon. Thus, like $\mathrm{C}$ and $\mathrm{Si}$, it shows a marked propensity to form covalent, molecular compounds, but it differs sharply from them in having one less valence electron than the number of valence orbitals, a situation sometimes referred to as "electron deficiency". This has a dominant effect on its chemistry [34].

The structural chemistry of B-O compounds is characterized by an extraordinary complexity and diversity and vast numbers of predominantly organic compounds containing $\mathrm{B}-\mathrm{O}$ are known. $\mathrm{B}(\mathrm{OH})_{3}$ is a very weak monobasic and acts exclusively by hydroxyl-ion acceptance rather than proton donation.

$\mathrm{B}(\mathrm{OH})_{3}+2 \mathrm{H}_{2} \mathrm{O} \rightarrow \mathrm{H}_{3} \mathrm{O}^{+}+\mathrm{B}(\mathrm{OH})_{4}^{-} \quad \mathrm{pK}=9.25$

Its acidity is considerably enhanced by chelation with polyhydric alcohols (e.g. glycerol, mannitol) (see Scheme 1) and this forms the basis of its use in analytical chemistry; e.g. with mannitol pK drops to 5.15 indicating an increase in the acid equilibrium constant by a factor of more than $10^{4}$ [34]. Based on the above chemistry, many lithium borates represented by lithium bis(oxalate)borate (LiBOB) have been synthesized and developed in the last decade as lithium salts and additives in the electrolytes exhibiting unique properties such as excellent thermal stability, comparable ionic conductivity, cost-effectiveness and environmental benignity.

The classic milestone review of non-aqueous liquid electrolyte for lithium ion batteries was made by Kang Xu almost ten years ago summarizing some lithium salts such as lithium perchlorate $\left(\mathrm{LiClO}_{4}\right)$, lithium hexafluoroarsenate $\left(\mathrm{LiAsF}_{6}\right)$, lithium tetrafluoroborate $\left(\mathrm{LiBF}_{4}\right)$, lithium trifluoromethanesulfonate (LiTf), lithium bis(trifluoromethanesulfonyl)imide (LiTFSI), lithium hexafluorophosphate $\left(\mathrm{LiPF}_{6}\right)$, and lithium bis(oxalate)borate (LiBOB) [5]. Then in 2011, Liu et al. presented an overview of the above lithium salts again and lithium oxalyldifluoroborate (LiDFOB) as well [35]. In terms of polymeric electrolytes, Wright described the advantages and characteristics of employing poly(ethylene oxide) (PEO) as all solid polymer electrolytes early in 1998 [36]. Then Song summarized the gel-type polymer electrolytes such as poly(ethylene oxide) (PEO), poly(acrylonitrile) (PAN), poly(methyl methacrylate) (PMMA) and poly(vinylidene fluoride) (PVDF)-based electrolytes in 1999 [30]. Recently, the research on polymer electrolytes and its progress was summarized again in 2011 by Scrosati [37]. Some other reviews related to the lithium ion battery electrolytes were also reported such as a review on electrolyte additives by Zhang [8] and another review on room temperature ionic liquids (RTILs) by Lewandowski [38]. Very recently, Gores gave a very brief summary on his lithium borates and ionic liquids synthesized in his lab [39]. To the best of our knowledge, no review articles on lithium borate salts have been systematically concluded till now.

Lithium borate salts have been arousing intensive interest in the lithium battery field due to their unique properties such as excellent thermal stability, comparable ionic conductivity, costeffectiveness, environmental benignity and favorable SEI forming properties when compared to the conventional LiFP 6 salt [40-58]. Herein, the recent progress of many lithium borate salts and their potential application in lithium batteries are summarized in this review. It is aimed at providing a comprehensive understanding of the key advancements achieved in this area of lithium borate salts as well as their potential application in high performance lithium batteries. This review will also incorporate preliminary
$\left.\right|_{\mathrm{F}} ^{\mathrm{F}} \mathrm{Li}_{\mathrm{F}}^{+}$

$\mathrm{LiBF}_{4}$

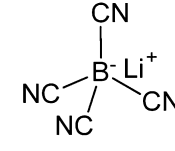

$\mathrm{LiB}(\mathrm{CN})_{4}$
LiBOB<smiles>O=C1O[B-]2(OC1=O)OC(=O)C(=O)O2</smiles><smiles></smiles>

LiDFOB
Scheme 2. Structural formulae of non-aromatic lithium borates.

results of recent work to identify single ion conductor, which has not received much attention yet. Our goal is therefore to provide a broad and concise scientific overview, encompassing the vast majority of research accomplished in the borate-based area over the last few years. So that new and established researchers in the battery area can obtain a clear perspective of this field.

According to the different chemical structures, the reported lithium borate salts can all be classified into three categories, i.e. non-aromatic lithium borates, aromatic lithium borates and singleion dominantly conducting polyborates, which will be discussed in detail in the following sections.

\section{Non-aromatic lithium borates}

The non-aromatic lithium borates are summarized in this section including the lithium salts such as $\mathrm{LiBF}_{4}, \mathrm{LiB}(\mathrm{CN})_{4}$, $\mathrm{LiBOB}$ and LiDFOB, whose chemical structures are depicted in Scheme 2 and their properties are listed in Table 1.

\subsection{Lithium tetrafluoroborate $\left(\mathrm{LiBF}_{4}\right)$}

Lithium tetrafluoroborate is an inorganic compound with the formula $\mathrm{LiBF}_{4}$ (shown in Scheme 2). It is very soluble in propylene carbonate and dimethyl carbonate. Its molecular weight is $93.9 \mathrm{Da}$, which is the smallest one among all the lithium salts. $\mathrm{LiBF}_{4}$ will melt at $293^{\circ} \mathrm{C}$ and then decompose. The decomposition temperature of $\mathrm{LiBF}_{4}$ is higher than that of $\mathrm{LiPF}_{6}$ and its toleration to moisture content can be up to $620 \mathrm{ppm}$ [33]. In early days, in order to overcome the drawbacks of $\mathrm{LiPF}_{6}$-based electrolytes, extensive attention had been paid to the development of $\mathrm{LiBF}_{4}[59,74,75]$. Its synthesis was first reported by Shapiro et al. in 1953, which is shown in Eq. (5) [76].

$3 \mathrm{Li}_{2} \mathrm{CO}_{3}+9 \mathrm{BF}_{3} \stackrel{300}{\longrightarrow} \mathrm{C} 6 \mathrm{LiBF}_{4}+3 \mathrm{CO}_{2}+(\mathrm{BOF})_{3}$

A green procedure to make $\mathrm{LiBF}_{4}$ was developed by Zhou et al. (see Eq. (6)) [77]. During this synthetic process, no organic solvent was used. $\mathrm{LiBF}_{4}$ is a white crystalline powder and its ORTEP (Oak Ridge Thermal Ellipsoid Plot Program for Crystal Structure Illustrations) diagrams are depicted in Fig. 2.

$$
\begin{aligned}
& 4 \mathrm{HF}+\mathrm{H}_{3} \mathrm{BO}_{3} \rightarrow \mathrm{HBF}_{4}+3 \mathrm{H}_{2} \mathrm{O} \\
& 2 \mathrm{HBF}_{4}+\mathrm{Li}_{2} \mathrm{CO}_{3} \rightarrow 2 \mathrm{LiBF}_{4}+\mathrm{H}_{2} \mathrm{O}+\mathrm{CO}_{2}
\end{aligned}
$$

$\mathrm{LiBF}_{4}$ was favored for low temperature applications because of its low viscosity when used in electrolytes [60,79]. Although $\mathrm{LiBF}_{4}$-based electrolyte provided lower ionic conductivity than $\mathrm{LiPF}_{6}$-based electrolyte, the cells based on $\mathrm{LiBF}_{4}$ electrolytes showed improved performance, not only at low temperatures but also, surprisingly, also at elevated temperatures up to $50^{\circ} \mathrm{C}$ as well $[33,61,80]$. Another advantage of $\mathrm{LiBF}_{4}$ was that the $\mathrm{LiBF}_{4}$-based electrolyte could passivate aluminum better than the $\mathrm{LiPF}_{6}$-based one [33,81]. Suppression of corrosion by adding $\mathrm{LiBF}_{4}$ was attributed to the formation of a stable passive layer on the surface of aluminum due to the reaction of aluminum with electrolyte and the decomposition of electrolyte solvent at high potentials. Behl and Plichta also reported the alleviated corrosion of aluminum when $\mathrm{LiBF}_{4}$ was used as an additive in the electrolyte [82,83]. 
Table 1

Physical and electrochemical properties of non-aromatic lithium borates. * Theoretical arithmetic, ${ }^{* *}$ 1,2-dimethoxy ethane (DME).

\begin{tabular}{|c|c|c|c|c|c|c|}
\hline Material & M. Wt. & $T_{\mathrm{d}}\left({ }^{\circ} \mathrm{C}\right)$ & Dissolving capacity & $\begin{array}{l}\text { Electrochemical } \\
\text { window (V vs. Li/Li+ })\end{array}$ & $\sigma\left(\mathrm{mS} \mathrm{cm}^{-1}\right)\left(25^{\circ} \mathrm{C}\right)$ & Refs. \\
\hline $\mathrm{LiBF}_{4}$ & 93.9 & 293 & $>1.0 \mathrm{M}(\mathrm{PC}, \mathrm{DMC})$ & 3.5 & $\begin{array}{l}3.4(\mathrm{PC}) \\
4.9(\mathrm{EC} / \mathrm{DMC})\end{array}$ & {$[33,59-61]$} \\
\hline $\mathrm{LiB}(\mathrm{CN})_{4}$ & 121.8 & 500 & $<1.0 \mathrm{M}(\mathrm{EC} / \mathrm{DMC})$ & $5.6^{*}$ & 14 & [62-64] \\
\hline LiBOB & 193.9 & 302 & $\begin{array}{l}0.8 \mathrm{M}(\mathrm{EC} / \mathrm{DMC}) \\
\mathrm{M}\left(\mathrm{DME}^{* *}\right)\end{array}$ & $\begin{array}{l}4.5(\mathrm{PC}) \\
>4.2(\mathrm{EC} / \mathrm{EMC})\end{array}$ & $\begin{array}{l}3.1(\mathrm{PC}) \\
9.0(\mathrm{DME}) \\
7.5(\mathrm{EC} / \mathrm{DMC})\end{array}$ & [65-68] \\
\hline LiDFOB & 143.8 & 240 & $\begin{array}{l}>1.2 \mathrm{M} \\
(\mathrm{EC} / \mathrm{DMC})\end{array}$ & $>4.2$ & $\begin{array}{l}8.8(\text { EC/DMC) } \\
8.2(\text { EC/PC/DMC) } \\
7.5(\text { EC/EMC })\end{array}$ & {$[25,69-73]$} \\
\hline
\end{tabular}

(a)

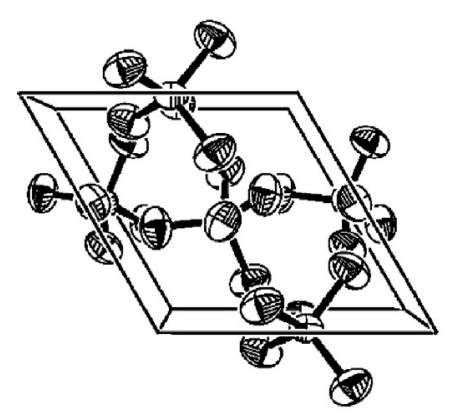

(b)

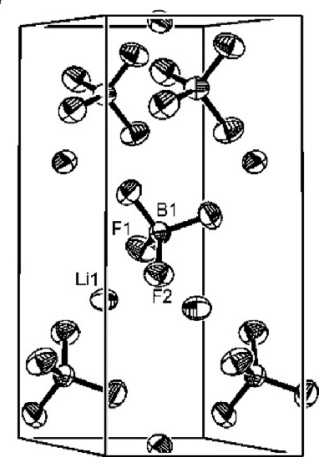

Fig. 2. ORTEP diagrams of the $\mathrm{LiBF}_{4}$ unit cell: (a) view along the $z$-axis and (b) the view perpendicular to the $z$-axis. Displacement ellipsoids are shown at a $50 \%$ probability level.

Reprinted with permission from Ref. [78]. Copyright 2006 American Chemical Society.

However, $\mathrm{LiBF}_{4}$ had a low anodic oxidization potential and its electrochemical window was only about $3.5 \mathrm{~V}$ vs. $\mathrm{Li} / \mathrm{Li}^{+}$, which meant that it could not be used in high voltage battery. In addition, it could not form a stable SEI layer on the graphite electrode, which had been a major obstacle to limit its extensive application $[59,61,83,84]$.

\subsection{Lithium tetracyanoborate $\left(\mathrm{LiB}(\mathrm{CN})_{4}\right)$}

Lithium tetracyanoborate is a chemical compound with the similar formula to $\mathrm{LiBF}_{4}$ with four cyano-chelating groups instead of four fluoro-substituents (shown in Scheme 2). It possesses relatively higher molecular weight of $121.8 \mathrm{Da}$ than that of $\mathrm{LiBF}_{4}$, but still smaller than that of $\mathrm{LiPF}_{6}(151.9 \mathrm{Da})$. The $\mathrm{LiB}(\mathrm{CN})_{4}$ was synthesized using $\mathrm{SiMe}_{3} \mathrm{CN}$ as the starting material, which underwent metathesis with $\mathrm{LiBF}_{4}$ at low temperatures in non-aqueous solvents (see Eq. (7)) [62].

$4 \mathrm{SiMe}_{3} \mathrm{CN}+\mathrm{LiBF}_{4} \rightarrow \mathrm{LiB}(\mathrm{CN})_{4}+4 \mathrm{SiMe}_{3} \mathrm{~F}$

Another way to produce $\mathrm{LiB}(\mathrm{CN})_{4}$ had been reported by Scheers, which was depicted in the following Eq. (8) [63].

$\mathrm{AgB}(\mathrm{CN})_{4}+\mathrm{LiCl} \rightarrow \mathrm{LiB}(\mathrm{CN})_{4}+\mathrm{AgCl}$

$\mathrm{LiB}(\mathrm{CN})_{4}$ is a thermally stable molecule that its decomposition temperature can be up to $500^{\circ} \mathrm{C}$. An ordered structure of $\mathrm{LiB}(\mathrm{CN})_{4}$ was found by Williams et al. and each Li was bonded to four $\mathrm{N}$ atoms and each $\mathrm{B}$ atom was bonded to four $\mathrm{C}$ atoms to form $\mathrm{LiN}_{4}$ and $\mathrm{BC}_{4}$ tetrahedra in solid state (see Fig. 3) [62]. Because of the strongly electron-withdrawing nitrile groups, $\mathrm{B}(\mathrm{CN})_{4}{ }^{-}$possesses a good resistance against anodic oxidation, which make this anion to have a wide electrochemical window up to $5.5 \mathrm{~V} \mathrm{vs.} \mathrm{Li} / \mathrm{Li}^{+}$. Besides, the delocalization of electrons in an anion reduced the dissociation

energy of lithium ion, which will be beneficial for its ionic conductivity. The affinity of $\mathrm{B}(\mathrm{CN})_{4}{ }^{-}$toward the lithium ion was smaller than that of $\mathrm{BF}_{4}{ }^{-}, \mathrm{PF}_{6}{ }^{-}$or $\mathrm{AsF}_{6}{ }^{-}$, which meant that $\mathrm{LiB}(\mathrm{CN})_{4}$ would have a high ionic conductivity [63].

The $\mathrm{LiB}(\mathrm{CN})_{4}$-based electrolyte could improve the performance of a $\mathrm{Li} / \mathrm{LiFePO}_{4}$ cell when compared to a $\mathrm{LiBF}_{4}$ based electrolyte [85]. For example, its electrolyte with polyethylene glycol dimethyl ether (PEGDME) was stable up to $4 \mathrm{~V} \mathrm{vs}$. $\mathrm{Li} / \mathrm{Li}^{+}$and showed excellent cycling performance, with a capacity retention of $99 \%$ over 22 cycles. In view of electrochemical stability and ionic conductivity, $\mathrm{B}(\mathrm{CN})_{4}{ }^{-}$is a contender for use in lithium batteries. Both the predicted oxidative stability and its weak coordination to lithium ions are valuable properties for these applications. In addition, Younesi et al. had investigated the $\mathrm{Li}-\mathrm{O}_{2}$ batteries using $\mathrm{LiB}(\mathrm{CN})_{4}$ as salt and polyethylene glycol dimethyl ether or tetraethylene glycol dimethyl ether as solvents [86]. However, hard X-ray photoelectron spectroscopy clearly showed that the $\mathrm{LiB}(\mathrm{CN})_{4}$ salt degraded during cycling. Besides, the possibility of forming hyper toxic cyanide and the risk of leakage will severely hamper its practical application in lithium ion batteries.

\subsection{Lithium bis(oxalate) borate (LiBOB)}

Lithium bis(oxalate)borate possesses two oxalate-coordination groups (shown in Scheme 2). Its molecular weight is $193.9 \mathrm{Da}$, which is a little bit higher than that of $\mathrm{LiPF}_{6}$ (151.9 Da). LiBOB has a high decomposition temperature of $302^{\circ} \mathrm{C}$. The solubility of LiBOB in carbonate solvents can reach $0.8 \mathrm{M}$ in EC/DMC and $1.6 \mathrm{M}$ in DME.

\subsubsection{Synthesis and properties}

LiBOB was once regarded as one of the most promising candidates for commercial use in the lithium batteries [23,25,66,87-92]. Its synthetic procedure was first reported by Lischka et al. in 1999, which was shown in Eq. (9) [93]. However, this reaction was carried out in an aqueous solution, it is quite tedious to get pure product without trace of water. Then Xu et al. adopted a non-aqueous reaction in aprotic solvent to obtain LiBOB with high purity shown in Eq. (10) [67]. Although this synthetic procedure was more complicated, there was no water involved in the reaction, which could meet the requirement of battery grade.

$$
\begin{aligned}
& \mathrm{LiOH}+2 \mathrm{H}_{2} \mathrm{C}_{2} \mathrm{O}_{4}+\mathrm{H}_{3} \mathrm{BO}_{3} \rightarrow \mathrm{LiB}\left[(\mathrm{OCO})_{2}\right]_{2}+4 \mathrm{H}_{2} \mathrm{O} \\
& \mathrm{LiB}\left(\mathrm{OCH}_{3}\right)_{4}+2\left(\mathrm{CH}_{3}\right)_{3} \mathrm{SiOOCCOOSi}\left(\mathrm{CH}_{3}\right)_{3} \\
& \stackrel{\mathrm{CH}_{3} \mathrm{CN}}{\longrightarrow} \mathrm{LiB}\left[(\mathrm{OCO})_{2}\right]_{2}+4 \mathrm{CH}_{3} \mathrm{OSi}\left(\mathrm{CH}_{3}\right)_{3}
\end{aligned}
$$

\subsubsection{Electrochemical performance}

2.3.2.1. Electrochemical performance as a main salt. The maximum concentration of LiBOB can be $0.8 \mathrm{M}$ in EC/DMC and 1.6 M in DME, 
(a)

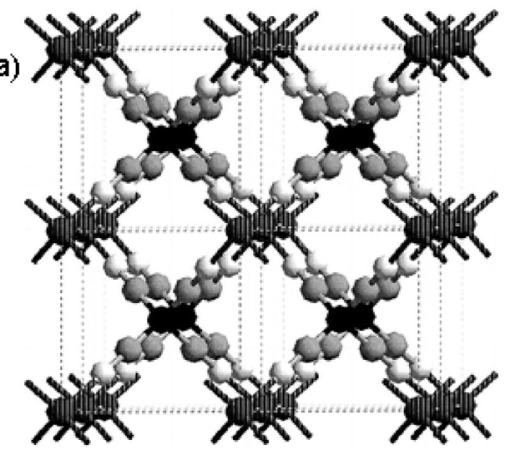

(b)

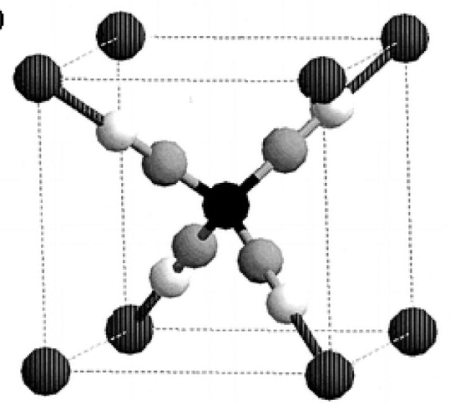

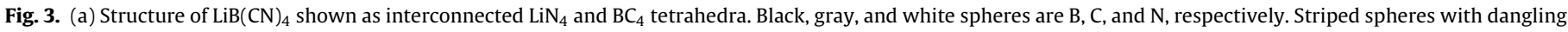
bonds at the corners are the Li atoms. (b) Unit cell of $\mathrm{LiB}(\mathrm{CN})_{4}$.

Reprinted with permission from Ref. [62]. Copyright 2000 American Chemical Society.

whose ionic conductivity reaches $7.5 \mathrm{mS} \mathrm{cm}^{-1}$ and $9.0 \mathrm{mS} \mathrm{cm}^{-1}$, respectively. In addition, LiBOB could remain stable in organic solvents and the electrochemical window of LiBOB-PC is higher than $4.5 \mathrm{~V}$ vs. $\mathrm{Li} / \mathrm{Li}^{+}$[67]. A difference between $\mathrm{LiBOB}$ and $\mathrm{LiPF}_{6}$ is that at the anode side the $\mathrm{BOB}^{-}$anion is starting to reductively decompose at voltages of around $1.75 \mathrm{~V} \mathrm{vs}$. $\mathrm{Li} / \mathrm{Li}^{+}$(see Fig. 4). Moreover, the formation of the favorable SEI was completed at potentials even around $0.50 \mathrm{~V}$ vs. $\mathrm{Li} / \mathrm{Li}^{+}$and it was confirmed that $\mathrm{BOB}^{-}$anion played a critical role in the effectiveness of the formed SEI, which was robust to protect the graphite structure without solvent co-intercalation and exfoliation even in PC $[67,68,88,94]$. The highest occupied molecular orbital (HOMO) and lowest unoccupied molecular orbital (LUMO) of the $\mathrm{BOB}^{-}$anion are depicted in Fig. 5. Investigation of the electronic structures of the anion and the radical revealed that the HOMO of the anion expanded over practically the entire molecule, whereas the radical LUMO was restricted to one of the oxalato groups. Comparing the SEI components of graphite anodes in $\mathrm{LiPF}_{6}$ and LiBOB electrolytes obtained by XPS analysis, Xu et al. came to a conclusion that the content of semicarbonate-like compounds significantly increased in the SEI due to the presence of $\mathrm{BOB}^{-}$anion [94]. Those semicarbonate-like compounds could dominate the chemical composition of the new SEI, and render the SEI stronger protection from solvent intercalation and solvent decomposition. Besides, LiBOB was reported to passivate aluminum current collector [23].
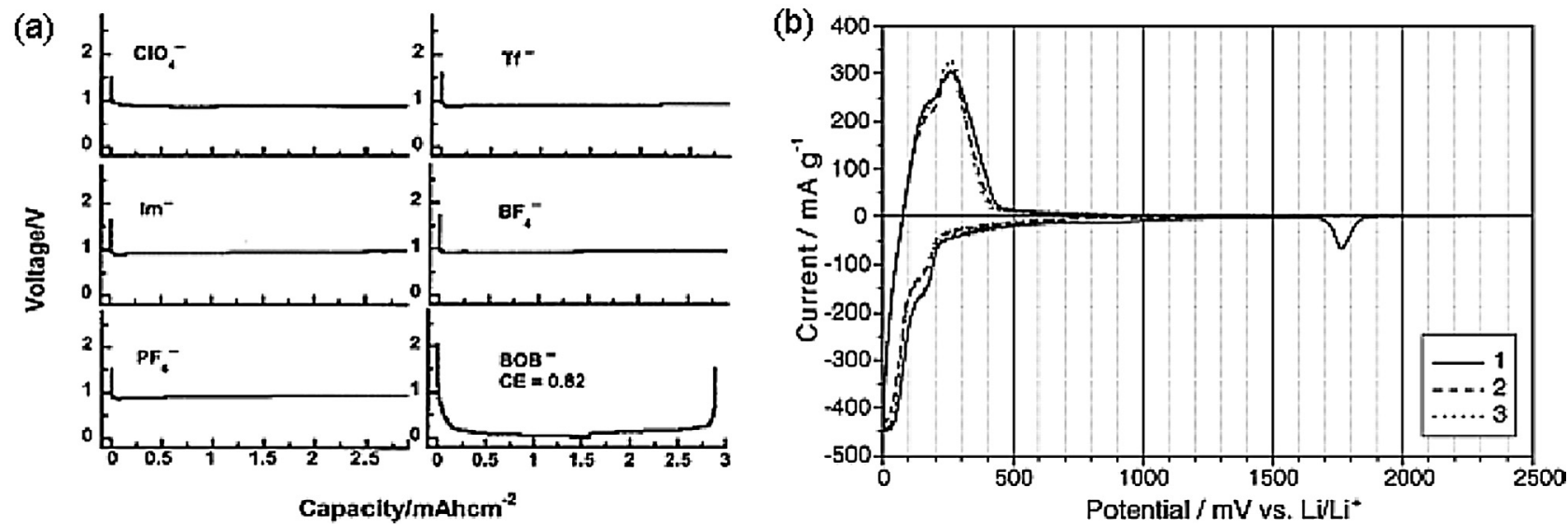

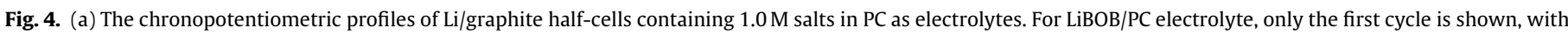

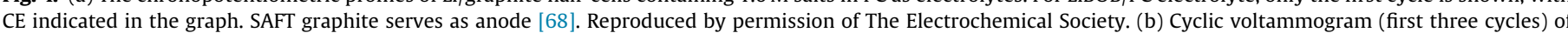
MCMB composite electrode in LiBOB/EC-EMC (scan rate: $0.1 \mathrm{mV} \mathrm{s}^{-1}$ and $0-2000 \mathrm{mV}$ ).

Reprinted from Ref. [88], Copyright (2006), with permission from Elsevier.

a)

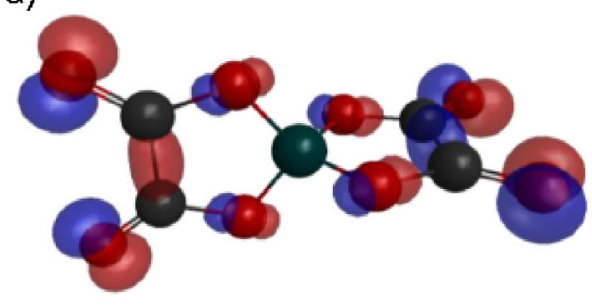

b)

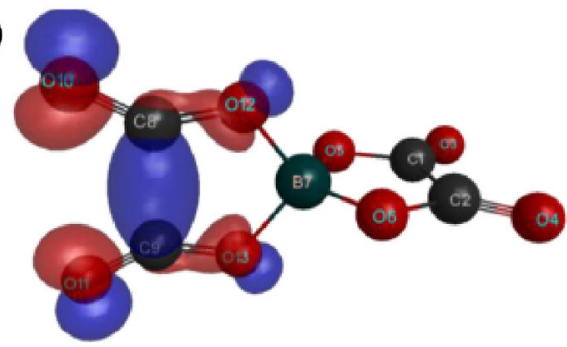

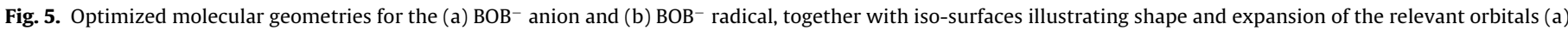
$\mathrm{HOMO}$ of $\mathrm{BOB}^{-}$and (b) LUMO of the $\mathrm{BOB}^{-}$radical.

Reprinted from Ref. [26], Copyright (2013), with permission from Elsevier. 
The development of secondary lithium batteries operated in relatively high temperature ranges represents an interesting alternative to state-of-the-art battery technology. LiBOB is one of the very promising candidates owing to its excellent thermal stability. The cathode material $\mathrm{LiFePO}_{4}$ possesses significantly high temperature stability up to $180^{\circ} \mathrm{C}$. The combination of $\mathrm{LiFePO}_{4}$ with thermally stable LiBOB salts in PC was cycled at relatively higher temperature up to $120^{\circ} \mathrm{C}$ [95]. In addition, successful cycling at $100^{\circ} \mathrm{C}$ with large capacity and small polarization was achieved using $1 \mathrm{M} \mathrm{LiBOB}$ in EC [96]. Belharouak also proved that the batteries operating at $55^{\circ} \mathrm{C}$ using $0.7 \mathrm{M}$ LiBOB in EC:PC:DMC electrolytes showed much lower capacity fading than the corresponding analogs of $\mathrm{LiPF}_{6}$ due to the suppression of iron dissolution [97]. Such effect has been recently confirmed in large cells that were also exhibiting significantly enhanced safety characteristic [98], which was in agreement with previous accelerating rate calorimetry (ARC) studies on the reaction between $\mathrm{LiFePO}_{4}$ and $\mathrm{LiBOB}$ in EC/DEC electrolyte [99]. These findings provided valuable information for the high temperature application in high power devices such as electric vehicles or measurement tools in oil well drilling.

Spinel-type lithium manganese oxide $\left(\mathrm{LiMn}_{2} \mathrm{O}_{4}\right)$ and lithium nickel manganese oxide ( $\left.\mathrm{LiNi}_{0.5} \mathrm{Mn}_{1.5} \mathrm{O}_{4}\right)$ are the most promising cathode materials for large-format lithium ion batteries for electric vehicles (EV) due to its cost-effectiveness, facile production, high discharge voltage plateau $\left(\sim 4.0 \mathrm{~V}\right.$ vs. $\mathrm{Li} / \mathrm{Li}^{+}$and $\sim 4.8 \mathrm{~V}$ vs. $\mathrm{Li} / \mathrm{Li}^{+}$, respectively) and environmental benignity compared to other cathode materials [100-103]. The $\mathrm{LiMn}_{2} \mathrm{O}_{4}$ based lithium batteries using conventional $\mathrm{LiPF}_{6}$-based electrolytes suffer from poor cycling performance at elevated temperatures (above $55^{\circ} \mathrm{C}$ ). This is mainly caused by the Mn dissolution generated from HF, which is originated from thermal decomposition of the $\mathrm{LiPF}_{6}$ salt at elevated temperatures. Fortunately, it was reported that the cell using LiBOB-based electrolyte maintained stable performance at elevated temperatures due to excellent thermal stability and absence of HF [92].

The above mentioned spinel-type lithium nickel manganese oxide $\left(\mathrm{LiNi}_{0.5} \mathrm{Mn}_{1.5} \mathrm{O}_{4}\right)$ belongs to the $5 \mathrm{~V}$ high-voltage class cathode materials. To seek the promising candidate for $5 \mathrm{~V}$ electrolytes, Cui et al. chose LiBOB as the lithium salt, $\gamma$-butyrolactone (GBL) and sulfolane (SL) as supporting electrolyte solvents, and linear DMC as the third supporting electrolyte solvent to lower the viscosity [104]. The novel electrolyte exhibiting excellent cycling performance would be an alternative electrolyte for $5 \mathrm{~V}$ high-voltage lithium ion batteries.

Apart from traditional solvent, LiBOB can also be used for the silicon-based and ionic liquids-based (ILs) electrolyte [85,105]. Kusachi et al. investigated the performance of LiBOB in one of the silicon-based electrolytes, tris(ethylene glycol)-substituted trimethylsilane [22]. The SEI characteristics and chemical components of both electrodes were investigated by X-ray photoelectron spectroscopy (XPS) and X-ray diffraction (XRD). The SEI components on the anode were similar to those using carbonate LiBOB electrolytes which consisted of lithium oxalate, lithium borooxalate, and $\mathrm{Li}_{x} \mathrm{BO}_{y}$. Ionic liquids consisting of organic cation and inorganic anion have attracted a great deal of attention owing to their highly flame-resistant properties, negligible vapor pressure and high thermal stability, which make them attractive candidates for safe lithium ion battery electrolytes [106-110]. Saruwatari et al. have studied LiBOB dissolving in 1-ethyl-3-methyl-imidazolium tetrafluoroborate $\left(\mathrm{EMIBF}_{4}\right)[85,105]$, and they came to a conclusion that these electrolytes had high lithium ion conductivity. Furthermore, Saruwatari confirmed that the addition of LiBOB to $\mathrm{EMIBF}_{4}$ suppressed the reaction of lithium metal with $\mathrm{EMI}^{+}$cation.

2.3.2.2. Electrochemical performance as an additive. The LiBOB has also been attracted considerable attention as an electrolyte additive to provide some specific function $[22,111,112]$, which is illustratively presented in Fig. 6. LiBOB has proven its ability of forming a stable SEI film on the graphite surface as an additive. Only $2 \mathrm{wt} . \%$ $\mathrm{LiBOB}$ to the state-of-the-art $\mathrm{LiPF}_{6}$ electrolytes was enough to suppress the extensive solvent decomposition, which could cause graphite exfoliation destruction. In addition, it was also demonstrated that LiBOB additive in the $\mathrm{LiPF}_{6}$-electrolyte improved the cycling performance of the cathodes. The reason why LiBOB additive can make the batteries working at high temperature and high voltage was further proved by Pieczonka [113]. LiBOB can trap $\mathrm{PF}_{5}$ and HF, which are generated from the decomposition of $\mathrm{LiPF}_{6} \mathrm{PF}_{5}$ tends to oxidize the carbonate solvents and $\mathrm{HF}$ is corrosive to the metal components in the cathodes. Pieczonka demonstrated that utilizing this peculiarity of LiBOB, the high-voltage half-battery containing manganese as positive cathode delivered an improved cycle life. The shortcomings of LiBOB such as low solubility, low ionic conductivity and decomposition limited its application as full lithium salts. However, LiBOB additive (between $0.1 \mathrm{M}$ and $0.25 \mathrm{M}$ concentration) in $\mathrm{LiPF}_{6}$-electrolyte played a synergetic role in stabilizing battery impedance and improving the cycling performance, especially at elevated temperatures, which were also reported by Shieh et al. [114]. When the 18650-type batteries using $\mathrm{LiMn}_{2} \mathrm{O}_{4}$ cathode cycled after 250 cycles at $55^{\circ} \mathrm{C}$, a large amount of mud-like SEI was formed on the anode surface in pure $\mathrm{LiPF}_{6}$ electrolyte system, which was different from that in LiBOB-containing systems revealing a clean surface on $\mathrm{LiMn}_{2} \mathrm{O}_{4}$. The morphology indicated the different formation and decomposition mechanisms of passive film on electrodes in LiBOB-based electrolyte systems, which accordingly resulted in improved electrochemical performance.

A major challenge for fabricating high energy density batteries is to find suitable electrolytes that can match well with the high-voltage spinel cathode materials such as $\mathrm{LiNi}_{0.5} \mathrm{Mn}_{1.5} \mathrm{O}_{4}$, $\mathrm{LiCoPO}_{4}$, and $\mathrm{LiMnFePO}_{4}$, whose charging/discharging voltages are higher than $4.0 \mathrm{Vvs}$. Li/ $/ \mathrm{Li}^{+}$. However, conventional $\mathrm{LiPF}_{6}$ based electrolytes suffer from chemical degradation at higher voltages and elevated temperatures $\geq 60^{\circ} \mathrm{C}$. The instability of above-mentioned electrolyte is particularly detrimental to the operation of highvoltage spinel cathodes (shown in Fig. 6). Incorporation of $3 \mathrm{wt}$ \% of LiBOB in conventional electrolyte solutions improved the cycling ability of $\mathrm{LiCOPO}_{4}$ electrode at high voltage $\left(5.2 \mathrm{~V}\right.$ vs. $\left.\mathrm{Li} / \mathrm{Li}^{+}\right)$and showed an improved capacity retention from $30 \%$ to $74 \%$ after 25 cycles [116]. LiBOB was also investigated as an additive to improve the cycling performance of $\mathrm{LiNi}_{0.5} \mathrm{Mn}_{1.5} \mathrm{O}_{4}$ cathode at high voltage (4.9 V Vs. $\left.\mathrm{Li} / \mathrm{Li}^{+}\right)$[117]. Incorporation of low concentrations of LiBOB (0.25-1.0 wt.\%, ) resulted in a significant improvement in the capacity retention and cycling efficiency of $\mathrm{LiNi}_{0.5} \mathrm{Mn}_{1.5} \mathrm{O}_{4} / \mathrm{Li}$ cells. Electrochemical impedance spectroscopy indicated that the addition of LiBOB decreased cell impedance. Ex situ surface analysis of cycled cells suggested that the cathode surface films were thinner in cells cycled with addition of LiBOB. The addition of LiBOB inhibited detrimental reactions of the electrolyte with the surface of $\mathrm{LiNi}_{0.5} \mathrm{Mn}_{1.5} \mathrm{O}_{4}$ cathodes at high potentials [118,119]. $1.0 \mathrm{wt} . \%$, LiBOB addition to the $\mathrm{LiPF}_{6}$ electrolyte was reported to dramatically improve the cycling lives of $\mathrm{Li}_{1-\chi} \mathrm{Ni}_{0.42} \mathrm{Fe}_{0.08} \mathrm{Mn}_{1.5} \mathrm{O}_{4}$ (LNFMO) Igraphite full-cells at $30^{\circ} \mathrm{C}$ and $45^{\circ} \mathrm{C}$ over 80 cycles. The capacity retention increased from $18 \%$ to $80 \%$ at $30^{\circ} \mathrm{C}$ and $5-40 \%$ at $45^{\circ} \mathrm{C}$, respectively [113]. It was demonstrated that the LiBOB additive could scavenge the $\mathrm{PF}_{5}$ that initiated the decomposition of electrolyte solvent and stabilize the electrolyte and the SEI on the graphite electrode against the deposition effects of the dissolved Mn [113].

2.3.2.3. Performance in gel or solid polymer electrolytes. The use of a gel or solid polymer electrolyte (GPE and SPE) to replace the conventional liquid electrolyte may help to tackle several problems: (i) suppression of lithium dendrites' engender 


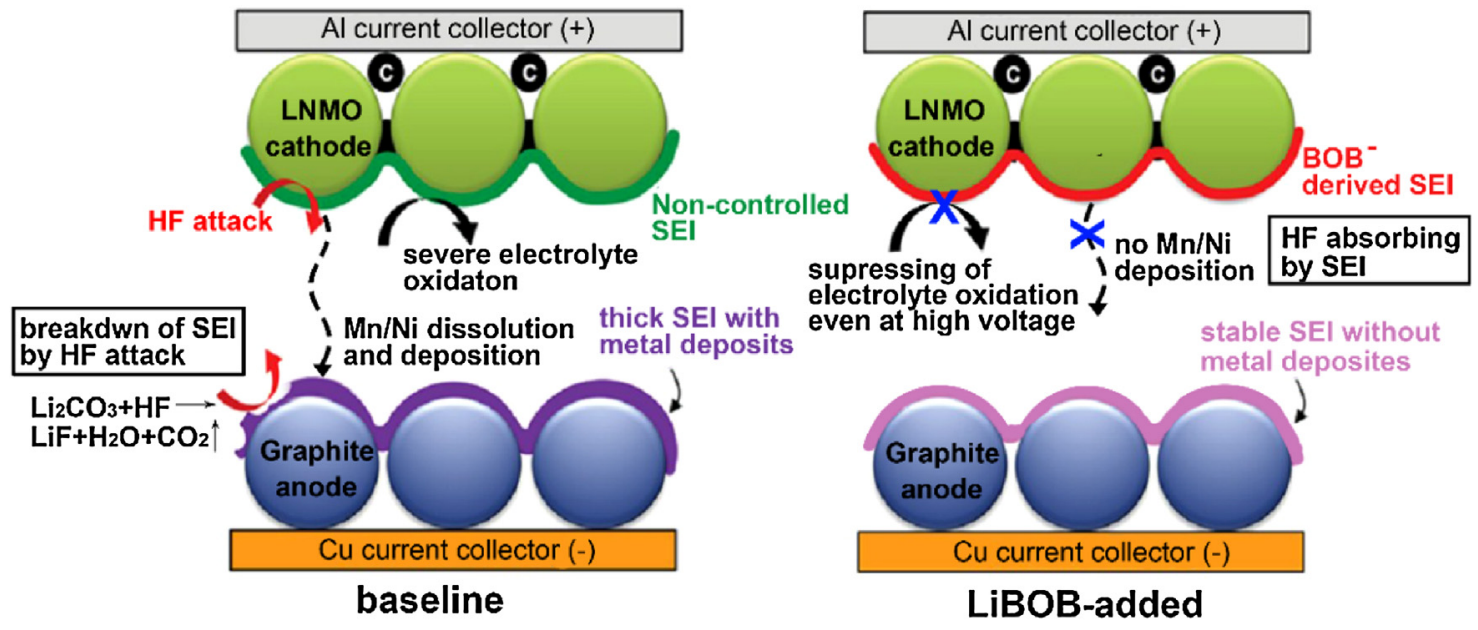

Fig. 6. Schematic illustration of unique functions of $\mathrm{LiBOB}$ additive in a graphite/ $/ \mathrm{LiNi}_{0.5} \mathrm{Mn}_{1.5} \mathrm{O}_{4}$ cell. Adapted from Ref. [115] with permission of The Royal Society of Chemistry.

and growth; (ii) alleviation of interfacial reactivity between the electrode and liquid electrolytes due to the least use of alkyl carbonate solvents; (iii) improvement of safety issues, in addition to suppression of lithium dendrites, the quasi-solidstate construction of a polymer electrolyte is more tolerant to mechanical deformation; (iv) better shape flexibility and manufacturing integrity. Many reviews had elaborated the recent progress in polymer electrolyte [5,120-125]. Poly(vinylidene fluoride) (PVDF), poly(vinylidene fluoride-co-hexafluoropropylene) (PVDF-HFP), poly(ethyleneoxide) (PEO), polyacrylonitrile (PAN) and poly(methyl methacrylate) (PMMA) have been widely studied as polymer matrices for GPEs in order to make them feasible for commercial applications.

The solvent-free, lithium-conducting polymer electrolytes had been prepared in professor Scrosati's group by hot-pressing a blend of PEO (molecular weight: $1 \times 10^{5}$ ) and LiBOB salt [126]. The (PEO) ${ }_{n}$-LiBOB polymer electrolytes possessed conductivity values varying from $10^{-5}$ to $10^{-3} \mathrm{Scm}^{-1}$ in a temperature range from $30^{\circ} \mathrm{C}$ to $80^{\circ} \mathrm{C}$. This high ionic conductivity was attributed to the remarkable amorphization effect on the PEO host induced by the $\mathrm{BOB}^{-}$anion. These (PEO) ${ }_{n}$-LiBOB polymer electrolytes exhibited lithium-ion transference number values ranging from 0.25 to 0.30 independent of the selected EO/Li molar ratio and operating temperature. These values were higher than the previous reported values for common PEO-LiX systems [127,128], attributed to the large $\mathrm{BOB}^{-}$anion, whose mobility was lower than that of more common $\mathrm{X}^{-}$anions. Considering all these favorable properties, these (PEO) ${ }_{n}$ LiBOB membranes appeared promising for solid polymer electrolytes of lithium batteries operating at high and medium temperatures. Tetrasiloxanes and trisiloxanes containing oligoether chains of various lengths $-\left(\mathrm{CH}_{2} \mathrm{CH}_{2} \mathrm{O}\right)_{n}-(n=2-7)$, were synthesized and doped with LiBOB salt as possible electrolytes for lithium batteries [129]. Conductivity data showed that these low viscosity materials (less than $10 \mathrm{cP}$ ) had some of the highest conductivities ever reported for polymeric electrolytes approaching $1 \times 10^{-3} \mathrm{~S} \mathrm{~cm}^{-1}$ at $37^{\circ} \mathrm{C}$. Conductivity vs. temperature plots of the doped compounds fit the semi-empirical Vogel-Tammann-Fulcher (VTF) equation indicating the ions mobility had coupling interaction with the motion of the polymer chains $[130,131]$.

The characterization of a low cost and very safe electrolyte prepared via the dissolution of LiBOB in a tetraethylene glycol dimethylether (LiBOB:TEGDME $=1: 4, \mathrm{w} / \mathrm{w}$ ) had been reported [52]. It was demonstrated that the electrolyte had conductivity ranging between $10^{-3} \mathrm{~S} \mathrm{~cm}^{-1}$ and $10^{-2} \mathrm{~S} \mathrm{~cm}^{-1}$ and a thermal stability as high as $180^{\circ} \mathrm{C}$. Sweep voltammetry of the electrolyte showed anodic oxidization stability extending over $4.6 \mathrm{~V}$ vs. $\mathrm{Li} / \mathrm{Li}^{+}$and cathodic peak at about $1.5 \mathrm{~V}$ vs. $\mathrm{Li} / \mathrm{Li}^{+}$relating to the reductive decomposition of LiBOB salt. Moreover, $\mathrm{LiFePO}_{4}$ cathode operated well in a lithium cell using the TEGDME-LiBOB electrolyte. Polymer gel electrolytes consisting of poly (2-ethoxyethyl methacrylate), LiBOB and different aprotic solvents (propylene carbonate, ethylene carbonate and dimethyl carbonate) had been prepared by a facile radical polymerization for lithium ion batteries operating at the elevated temperature of $70^{\circ} \mathrm{C}$ [132]. The maximum value of the ionic conductivity was $2.4 \times 10^{-3} \mathrm{~S} \mathrm{~cm}^{-1}$ at $70^{\circ} \mathrm{C}$ for PEOEMA-DEC/EC-LiBOB (34:22/40:4 mol.\%) sample. The electrochemical stability toward oxidation was up to $5.1 \mathrm{~V}$ (vs. $\mathrm{Li} / \mathrm{Li}^{+}$). As reported polymer electrolytes delivered higher electrochemical and thermal stability compared to the conventional liquid electrolytes such as DEC/EC-LiBOB.

LiBOB was also studied with PMMA to obtain the PMMA gel polymer electrolytes [51]. The ionic conductivity of the 20 wt.\%, PMMA containing GPE reached $3.58 \mathrm{mS} \mathrm{cm}^{-1}$ at $100^{\circ} \mathrm{C}$. Its conductivity-temperature relationship obeyed VTF equation, which indicated that the polymer chain motions contributed to the ion mobility. The GPE showed stability up to $4.7 \mathrm{~V} \mathrm{vs.} \mathrm{Li} / \mathrm{Li}^{+}$ and the lithium ion transference number was 0.46 at $25^{\circ} \mathrm{C}$. This GPE was used as an electrolyte in a $\mathrm{Li} / \mathrm{LiCoO}_{2}$ cell, and subjected to charge-discharge cycling between $4.2 \mathrm{~V}$ and $3.0 \mathrm{~V}$ with stable capacity of $\sim 130 \mathrm{~mA} \mathrm{~h}^{-1}$ over 20 cycles.

Ghosh et al. reported an average transference number for LiBOB added $\mathrm{PEO}_{\mathrm{b}}$-(PMMA-ran-PMAALi) as 0.89 and 0.75 at $25^{\circ} \mathrm{C}$ and $60^{\circ} \mathrm{C}$ respectively [133]. The higher transference number obtained in this work may be attributed to the higher PMMA molecular weight $\left(\sim 1 \times 10^{6}\right)$ which contained longer molecular chains and specific chains. It was supposed that these longer chains could entangle to form helix, coiled and/or folded structures that could have a blocking effect to the transport of the large $\mathrm{BOB}^{-}$anion. The entanglements could immobilize the $\mathrm{BOB}^{-}$ions and thereby increased the transference number of the lithium ions.

It was demonstrated the overcharge tolerance of LiBOB battery was excellent, which was ascribed to the fact that the oxalate molecular moieties of LiBOB were preferably oxidized to produce $\mathrm{CO}_{2}$ by the oxygen released from the cathode, as shown in Eq. (11). This reaction produced $\mathrm{CO}_{2}$ very effectively (i.e., $1 \mathrm{~mol}$ salt for $4 \mathrm{~mol} \mathrm{CO}_{2}$ ). More importantly it generates much less heat (smaller enthalpy change) than the oxidization of solvents in the case of $\mathrm{LiPF}_{6}$ battery. As a result of the mild oxidization of LiBOB, the internal pressure was rapidly built up by the released $\mathrm{CO}_{2}$, which consequently opened safety vent before thermal runway occurs. 
(a)

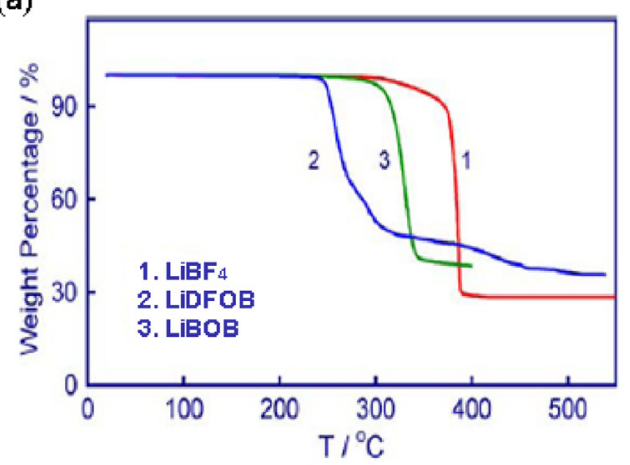

(b)

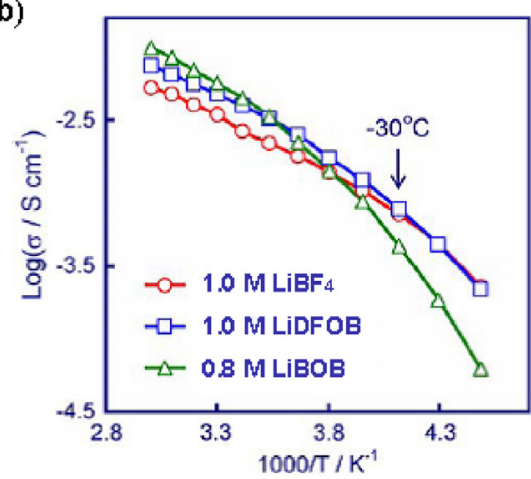

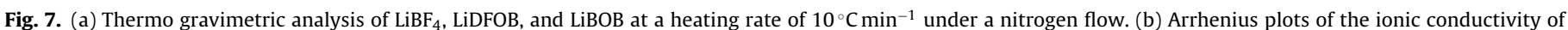
$\mathrm{LiBF}_{4}$, LiDFOB and LiBOB in a PC/EC/EMC (1:1:3, wt.) solvent mixture.

Reprinted from Ref. [72], Copyright (2006), with permission from Elsevier.

Considerable gas production was also observed in lithium ion cells based on $\mathrm{LiCoO}_{2}$ cathode by Wietlemann et al. [66,98,134]. So the batteries using LiBOB-based electrolytes were proposed to possess better safety characteristics.

$\mathrm{LiBOB} \stackrel{[\mathrm{O}]}{\longrightarrow} \mathrm{LiBO}_{2}+4 \mathrm{CO}_{2}$

In conclusion, LiBOB-based electrolytes possess special physicochemical property, electrochemical property and superior thermal stability. Particularly in PC-based electrolytes, LiBOB-based electrolytes allow the graphite as anode avoiding exfoliation owing to forming favorable SEI layer and endow batteries to have excellent cycling performance at elevated temperature. Meanwhile, LiBOB is environmental benign and not as sensitive to moisture as $\mathrm{LiPF}_{6}[21,92]$. However, the thick SEI layer formed in LiBOB-based electrolyte increased the interfacial impedance of the negative electrodes and the power capability of the lithium ion batteries was somehow affected. All these investigation and findings indicate that LiBOB will be widely used in next generation batteries, especially suitable in a large scale energy storage application.

\subsection{Lithium difluoro(oxalate) borate (LiDFOB)}

Lithium difluoro(oxalate) borate has one oxalate- and two fluoro-substituting groups (see Scheme 2), possessing the combined chemical structures of LiBOB and $\mathrm{LiBF}_{4}$ [38]. Its molecular weight is $143.8 \mathrm{Da}$, which is very close to than that of $\mathrm{LiPF}_{6}$ (151.9 Da). LiDFOB has a high decomposition temperature up to $240^{\circ} \mathrm{C}$. The solubility in carbonate solvents is much improved when compared to LiBOB and the maximum concentration of LiDFOB can reach $1.2 \mathrm{M}$ in EC/DMC.

\subsubsection{Synthesis and properties}

LiDFOB was synthesized by resultant mixture of oxalate acid and boric acid in a 3:2 molar ratio reacting with lithium fluoride [135]. High purity LiDFOB was obtained after recrystallization using a mixture of acetonitrile/toluene $(1: 1, \mathrm{v} / \mathrm{v})$.

$3 \mathrm{H}_{2} \mathrm{C}_{2} \mathrm{O}_{4}+2 \mathrm{H}_{3} \mathrm{BO}_{3} \rightarrow \mathrm{B}_{2}\left(\mathrm{C}_{2} \mathrm{O}_{4}\right)_{3} \stackrel{4 \mathrm{LiF}}{\longrightarrow} 2 \mathrm{LiDFOB}+\mathrm{Li}_{2} \mathrm{C}_{2} \mathrm{O}_{4}$

Aravindan et al. discovered another procedure to make LiDFOB using boron trifluoride diethyletherate and lithium oxalate in a 1:1 molar ratio as starting materials and the product was purified through extraction and recrystallization using DMC solvent [55]. The advantage of this procedure was that no solvent separation was involved any more.

$\mathrm{Li}_{2} \mathrm{C}_{2} \mathrm{O}_{4}+\mathrm{BF} 3 \mathrm{O}\left(\mathrm{CH}_{2} \mathrm{CH}_{3}\right)_{2} \rightarrow \mathrm{O}\left(\mathrm{CH}_{2} \mathrm{CH}_{3}\right)_{2}+\mathrm{LiF}+\mathrm{LiDFOB}$

\subsubsection{Electrochemical performance}

2.4.2.1. Electrochemical performance as a main salt. LiDFOB was first reported as an unique lithium salt by S.S. Zhang in 2006 for an improved electrolyte of Li-ion battery in terms of thermal stability, ionic conductivity, current collector compatibility and SEI forming properties [72]. This salt possessed the combined advantages of $\mathrm{LiBOB}$ and $\mathrm{LiBF}_{4}$ due to its chemical structure comprising both moieties of LiBOB and $\mathrm{LiBF}_{4}$. Compared with LiBOB, the salt was more soluble in linear carbonates and the resultant solution was less viscous, which resulted in improved low temperature and high rate performance. Compared with $\mathrm{LiBF}_{4}$, the salt was highly capable of stabilizing SEI on the surface of graphite anode, which enabled Li-ion cell to be operated stably at elevated temperatures.

The thermal stability of $\mathrm{LiBF}_{4}$, LiDFOB and LiBOB is shown in Fig. 7(a). Thermal decomposition of LiDFOB occurred at $240^{\circ} \mathrm{C}$, which was the lowest temperature among these three salts but still $40^{\circ} \mathrm{C}$ higher than that of the $\mathrm{LiPF}_{6}$ salt. Besides, Zhang also compared the conductivity behavior of $\mathrm{LiBOB} \mathrm{LiBF}_{4}$ and LiDFOB in PC/EC/DMC, respectively [72]. Their conductivities for these three salts were significantly influenced by the temperature (shown in Fig. 7(b)). LiBOB had the highest conductivity among the three electrolytes and LiDFOB was in middle above $10^{\circ} \mathrm{C}$, but the order changed to that the conductivity of LiDFOB was higher than that of $\mathrm{LiBOB}$ below $-30^{\circ} \mathrm{C}$. This behavior was attributed to the combined effect of salt dissociation and solution viscosity [55]. LiDFOB-based electrolyte possessed high conductivity and excellent capacity retention even at low temperature. Therefore, it was indicated that LiDFOB was a promising candidate for low temperature application. Furthermore, Zhang discovered that LiDFOB-based electrolyte could passivate the aluminum collector as LiBOB did at high voltage, which was attributed to the formation of a dense protecting layer on the aluminum surface through chemical combination of $\mathrm{Al}^{3+}$ and $\mathrm{B}-\mathrm{O}$ molecular moieties.

The LiDFOB-based electrolytes in various carbonate electrolytes had been investigated for $\mathrm{LiFePO}_{4} /$ artificial graphite (AG) cells by Li et al. in 2010 [25]. The $1 \mathrm{M}$ LiDFOB in EC/PC/DMC (1:1:3, $\mathrm{v} / \mathrm{v}$ ) electrolyte possessed comparably higher ionic conductivity $\left(8.25 \mathrm{mS} \mathrm{cm}^{-1}\right.$ at $\left.25^{\circ} \mathrm{C}\right)$. Both the $\mathrm{LiFePO}_{4} / \mathrm{Li}$ and $\mathrm{AG} / \mathrm{Li}$ half cells exhibited high coulombic efficiency and lower interfacial resistance, due to its relatively higher conductivity and better capability to form SEI film of low resistance. The $\mathrm{LiFePO}_{4} / \mathrm{AG}$ cells using this electrolyte displayed excellent capacity retention at $-10^{\circ} \mathrm{C}$, $25^{\circ} \mathrm{C}$ and even at elevated temperatures up to $65^{\circ} \mathrm{C}$. The rate performance of the cells using LiDFOB electrolyte was close to the cells that using $\mathrm{LiPF}_{6}$ electrolyte at $25^{\circ} \mathrm{C}$. Moreover, at the elevated temperature of $65^{\circ} \mathrm{C}$, the capacity retention of the cells with LiDFOB-based electrolyte was $88 \%$, which was much higher than 

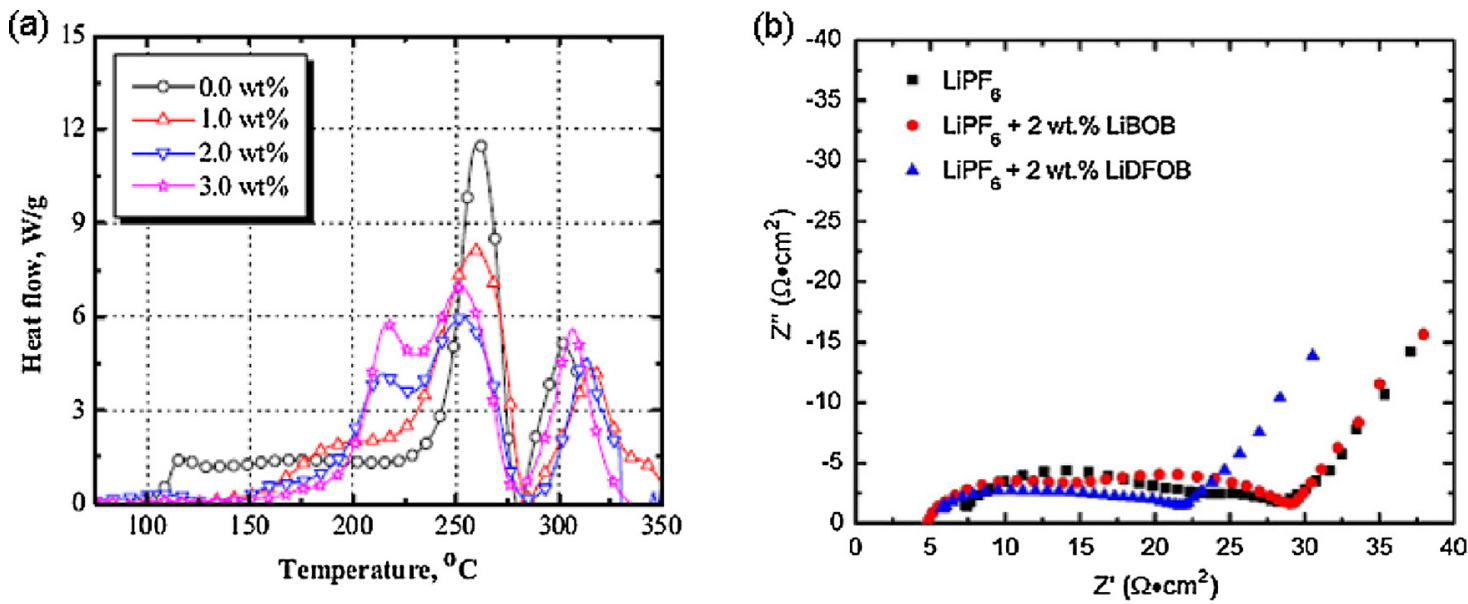

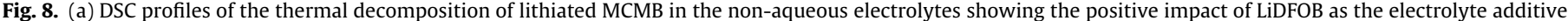

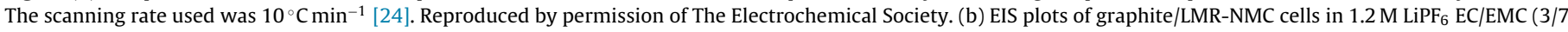

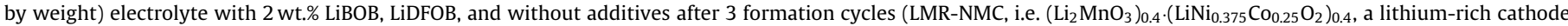
material designated as Toda HE5050).

Reprinted from Ref. [56], Copyright (2012), with permission from Elsevier.

that of $\mathrm{LiPF}_{6}$-based electrolyte (50\%). So this LiDFOB-based electrolyte was a promising electrolyte in $\mathrm{LiFePO}_{4} / \mathrm{AG}$ cells especially for high temperature application.

2.4.2.2. Electrochemical performance as an additive. LiDFOB can also be used as electrolyte additive to improve the high temperature performance. Prof. K. Amine disclosed that the addition of LiDFOB to the electrolyte significantly improved the interfacial thermal stability of the lithiated mesocarbon microbeads (MCMB) in EC/EMC electrolyte. The activation energy of the thermal decomposition reactions increased with the increasing concentration of LiDFOB from $0 \%$ to $3.0 \%$ [24].

Moreover, the cell using LiDFOB assisted electrolyte possessed low ohmic and charge-transfer resistance (shown in Fig. 8(b)). The EIS analysis and SEM observations on the cycled electrodes revealed that the thickness of SEI films on the surface of graphite was reduced in the presence of LiDFOB additive [56,57]. The utilization of LiDFOB dramatically enhanced the cycling performance with capacity retention of about $66.4 \%$ after more than 200 cycles at $60{ }^{\circ} \mathrm{C}[57]$.
The mechanism of LiDFOB stabilizing SEI is entirely based on a series of complicated exchange reactions, instead of the reduction as observed in the case of electrolyte additives such as vinylene carbonate. LiDFOB in the electrolyte simultaneously undergoes two chemical equilibria (1) and (2), as shown in Scheme 3, where both (I) and (II) can combine with the main SEI components, such as lithium semi-carbonate (III), to form more complicated and stable oligomers [24,25,73].

The mechanism of thermal stability enhancement for the LiDFOB additive based electrolyte and interface layers has been investigated by Xu and coworkers in 2011 [57]. It was verified by NMR measurements that the addition of LiDFOB to $\mathrm{LiPF}_{6}$-based electrolytes inhibited the autocatalytic thermal decomposition of the electrolyte, generating lithium tetrafluorooxalatophosphate $\left(\mathrm{LiPF}_{4} \mathrm{C}_{2} \mathrm{O}_{4}\right)$ and $\mathrm{LiBF}_{4}$ due to the synergistic effect between LiDFOB and $\mathrm{LiPF}_{6}$ at elevated temperature of $85^{\circ} \mathrm{C}$. The formation of borates or its derivative products resulting from the degradation of LiDFOB on both electrodes was also a leading factor for the improvement of the cycling performance at elevated temperature [57]. This improved performance was ascribed to the assistance of LiDFOB in forming favorable SEI layers on both anode and cathode

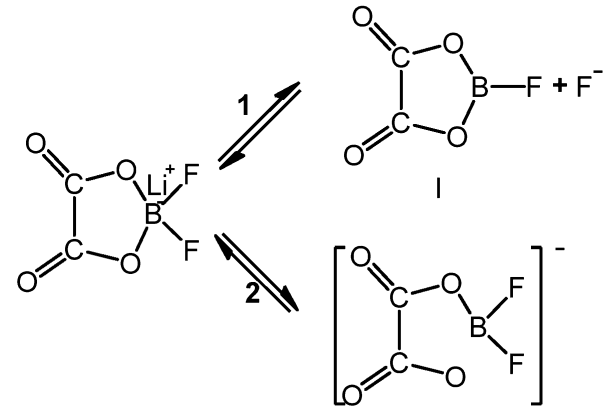

II<smiles>O=C(O)OCCOB(OC(=O)OCCOC(=O)O)OC(=O)OB(OC(=O)OCCOC(=O)O)OC(=O)OCCOC(=O)OCCOC(=O)OCCOC(=O)O</smiles>

Scheme 3. The probable SEI-forming mechanism of LiDFOB-based electrolytes.

Reprinted from Ref. [72], Copyright (2006), with permission from Elsevier. 
<smiles></smiles>

LiBBB<smiles>Fc1c(F)c(F)c2c(c1F)O[B-]1(O2)Oc2c(F)c(F)c(F)c(F)c2O1</smiles>

LiBTBB<smiles>O=C1O[B-]2(OC(=O)c3ccccc3O2)Oc2ccccc21</smiles>

LiBSB<smiles>Fc1cccc2c1O[B-]1(O2)Oc2cccc(F)c2O1</smiles>

LiBFBB<smiles>c1ccc2cc3c(cc2c1)O[B-]1(O3)Oc2cc3ccccc3cc2O1</smiles>

LiBNB<smiles></smiles>

LiBBPB<smiles></smiles>

\section{LiBDOB}

Scheme 4. Structural formulae of aromatic lithium borates.

and subsequently resulted in the enhancement of the thermal stability of the electrolyte.

In conclusion, the LiDFOB-based electrolytes have shown excellent electrochemical performance and their cells delivered improved cycling performance at high temperature and good safety characteristics owing to its combined advantages of LiBOB and $\mathrm{LiBF}_{4}[72]$. Therefore, it possesses a very promising prospect in lithium batteries, especially for electric vehicles. However, the investigation of LiDFOB-based electrolytes is not as intensive as for LiBOB-based electrolytes. In addition, their applications in high voltage electrolytes, gel and solid polymeric electrolytes or ionic liquid electrolytes and their related fundamental issues have not yet been discussed.

\section{Aromatic lithium borates}

The aromatic lithium borates are outlined in this section including lithium bis[1,2-benzenediolato (2-)-O, $\left.\mathrm{O}^{\prime}\right]$ borate (LiBBB), lithium bis[3-fluoro-1,2-benzenediolato (2-)-O, $\mathrm{O}^{\prime}$ ] borate (LiBFBB), lithium bis[tetrafluoro-1,2-benzenediolato (2-)-O, $\mathrm{O}^{\prime}$ ] borate (LiBTBB), lithium bis[2,2'-naphthalenediolato (2-)-O, $\left.\mathrm{O}^{\prime}\right]$ borate (LiBNB), lithium bis(salicylate-2-) borate (LiBSB), lithium bis $\left[2,2^{\prime}\right.$-biphenyldiolato (2-)-O, $\left.\mathrm{O}^{\prime}\right]$ borate (LiBBPB), lithium [1,2benzenediolato (2-)-O, $\mathrm{O}^{\prime}$ oxalato] borate ( $\left.\mathrm{LiBDOB}\right)$. Their chemical structures and physical and electrochemical properties are presented in Scheme 4 and Table 2 respectively. There are two other aromatic lithium borates reported as additives, i.e. lithium salicylato-oxalato borate (LiSOB) and tris(pentafluorophenyl) borane (TPFPB), and their chemical structures are given in Scheme 5 .

\subsection{Lithium bis[1,2-benzenediolato (2-)-O,O'] borate (LiBBB)}

Lithium bis[1,2-benzenediolato(2-)-0,0'] borate possesses two pyrocatechol-chelating groups (shown in Scheme 4) [141]. Its molecular weight is $233.4 \mathrm{Da}$, which is relatively large consisting<smiles>O=C1O[B-]2(OC1=O)OC(=O)C(=O)O2</smiles><smiles>Fc1c(F)c(F)c(B(c2c(F)c(F)c(F)c(F)c2F)c2c(F)c(F)c(F)c(F)c2F)c(F)c1F</smiles>

Scheme 5. Structural formulae of aromatic lithium borate additives.

of two aromatic phenyl rings. LiBBB has a high decomposition temperature at $250^{\circ} \mathrm{C}$ [138]. Its solubility can reach $1.1 \mathrm{M}$ in PC.

The synthesis of LiBBB was reported by Wuhr, which was depicted in Eq. (14) as follows [142].

$$
\mathrm{LiOH}+\mathrm{B}(\mathrm{OH})_{3}+2 \mathrm{C}_{6} \mathrm{H}_{4}(\mathrm{OH})_{2} \rightarrow \mathrm{Li}\left[\mathrm{B}\left(\mathrm{C}_{6} \mathrm{H}_{4} \mathrm{O}_{2}\right)_{2}\right]
$$

LiBBB starts to decompose when the temperature come to $250{ }^{\circ} \mathrm{C}$, which made it possible candidate to replace $\mathrm{LiPF}_{6}$ when the battery is operated at elevated temperatures. In addition, ion pair formation is suppressed in LiBBB due to the charge delocalization of the large aromatic phenyl rings, which will be beneficial for the ionic conductivity. The solubility of this lithium salt in various carbonate solvents is more than $1 \mathrm{~mol} \mathrm{~L}^{-1}$.

In 1995, LiBBB was studied as a lithium salt in lithium batteries by Barthel and his coworkers [10]. They claimed that LiBBB could be used as a class of nontoxic, thermally, chemically, and electrochemically stable and inexpensive lithium salts compared to $\mathrm{LiPF}_{6}$ salt.

However, LiBBB showed poor electrochemical stability than $\mathrm{LiPF}_{6}$. The voltage window of LiBBB-based solutions was limited by the oxidation of the catechol moieties at about $3.6 \mathrm{~V} \mathrm{vs}$. $\mathrm{Li} / \mathrm{Li}^{+}$, independent of the solvent [10]. The voltage window was too low for its application in lithium ion batteries with strongly oxidizing cathode materials such as $\mathrm{LiMn}_{2} \mathrm{O}_{4}$, which required an electrochemical stability range of about $4-4.5 \mathrm{~V}$ vs. $\mathrm{Li} / \mathrm{Li}^{+}$. In order to increase the electrochemical stability at high voltage, fluorinated analogs were further investigated which would be discussed in the following section.

\subsection{Lithium bis[3-fluoro-1,2-benzenediolato (2-)-O,O'] borate (LiBFBB)}

LiBFBB is a kind of fluoro-substituted derivative of LiBBB with the molecular weight of 269.4 Da (shown in Scheme 4). It decomposes at $256^{\circ} \mathrm{C}$. Its synthesis was given below [142].

$\mathrm{LiOH}+\mathrm{B}(\mathrm{OH})_{3}+2 \mathrm{C}_{6} \mathrm{H}_{3} \mathrm{~F}(\mathrm{OH})_{2} \rightarrow \mathrm{Li}\left[\mathrm{B}\left(\mathrm{C}_{6} \mathrm{H}_{3} \mathrm{FO}_{2}\right)_{2}\right]$

As a fluorine substituent replaced a hydrogen substituent on the phenyl ring, the charge distribution of boron anion was more delocalized than that of LiBBB. Therefore, the solution composed of LiBFBB would have higher conductivity than that of LiBBB [40]. Even so, the voltage window was improved slightly to $3.75 \mathrm{~V}$ vs. $\mathrm{Li} / \mathrm{Li}^{+}$, which still could not meet the requirements of lithium ion battery despite minor advancement $[42,43,137]$.

\subsection{Lithium bis[tetrafluoro-1, 2-benzenediolato (2-)-O, $\mathrm{O}^{\prime}$ ] borate (LiBTBB)}

LiBTBB is the eight fluoro-substituted derivative of LiBBB with the molecular weight of 377.4 Da (see Scheme 4). LiBBB has a high decomposition temperature at $270^{\circ} \mathrm{C}$, but poor solubility in carbonate solvents. 
Table 2

Physical and electrochemical properties of the aromatic lithium borates.

\begin{tabular}{|c|c|c|c|c|c|c|}
\hline Material & M. Wt. & $T_{\mathrm{d}}\left({ }^{\circ} \mathrm{C}\right)$ & Dissolving capacity & $\begin{array}{l}\text { Electrochemical } \\
\left.\text { window (V vs. } \mathrm{Li} / \mathrm{Li}^{+}\right)\end{array}$ & $\sigma\left(\mathrm{mS} \mathrm{cm}^{-1}\right)\left(25^{\circ} \mathrm{C}\right)$ & Ref. \\
\hline LiBBB & 233.4 & 250 & $1.1 \mathrm{M}(\mathrm{PC})$ & 3.6 & $\begin{array}{l}2.4(\mathrm{PC}) \\
3.0(\mathrm{PC} / \mathrm{DMC}) \\
5.6(\mathrm{EC} / \mathrm{DMC})\end{array}$ & {$[10,42,43,136,137]$} \\
\hline LiBFBB & 269.4 & 256 & $0.2 \mathrm{M}(\mathrm{PC})$ & 3.75 & $2.0(P C)$ & {$[40,137]$} \\
\hline LiBTBB & 377.4 & 270 & $\begin{array}{l}0.3 \mathrm{M}(\mathrm{PC}) \\
<0.3 \mathrm{M}(\mathrm{EC} / \mathrm{DMC})\end{array}$ & 4.1 & 11 (DME) & {$[41,137]$} \\
\hline LiBNB & 334.1 & 320 & $0.5 \mathrm{M}(\mathrm{EC} / \mathrm{DMC})$ & 3.8 & 4.5 (EC/DMC) & {$[136,138]$} \\
\hline LiBSB & 290.0 & 290 & $\begin{array}{l}1.34 \mathrm{M}(\mathrm{PC} / \mathrm{DME}) \\
1.41 \mathrm{M}(\mathrm{EC} / \mathrm{DME})\end{array}$ & 4.5 & $\begin{array}{l}4.27 \text { (PC/DMC) } \\
5.08 \text { (EC/DMC) }\end{array}$ & {$[42,138]$} \\
\hline LiBBPB & 386.1 & 370 & $0.3 \mathrm{M}(\mathrm{PC} / \mathrm{DME})$ & 4.1 & $1.0(\mathrm{PC} / \mathrm{DME})$ & {$[136,138]$} \\
\hline LiBDOB & 213.7 & 256 & $\begin{array}{l}0.274 \mathrm{M}(\mathrm{PC}) \\
0.302 \mathrm{M}(\mathrm{PC} / \mathrm{DME})\end{array}$ & - & $\begin{array}{l}5.36(\mathrm{PC}) \\
6.21 \text { (PC/DME) } \\
4.96 \text { (EC/DME) }\end{array}$ & {$[139,140]$} \\
\hline
\end{tabular}

LiBTBB was first synthesized by Barthel in 1996 [41]. The process of synthesis is depicted as follows.

$$
\begin{aligned}
& \mathrm{C}_{6} \mathrm{~F}_{5} \mathrm{OK}+\mathrm{C}_{2} \mathrm{H}_{4} \mathrm{O} \stackrel{\text { DMSO }}{\longrightarrow} \mathrm{C}_{8} \mathrm{H}_{4} \mathrm{~F}_{4} \mathrm{O}_{2}+\mathrm{KF} \\
& \mathrm{LiB}\left(\mathrm{OCH}_{3}\right)_{4}+2 \mathrm{C}_{8} \mathrm{H}_{4} \mathrm{~F}_{4} \mathrm{O}_{2} \stackrel{\mathrm{CH}_{3} \mathrm{CN}}{\longrightarrow} \mathrm{LiBTBB}+4 \mathrm{CH}_{3} \mathrm{OH}
\end{aligned}
$$

Compared with LiBFBB, the molecule of LiBTBB has more fluorine substituents. Despite the lower mobility of the larger anion, its extensive charge delocalization in its anion caused by strongly electron withdrawing substituents made it to show weak anion solvent interaction. Due to this particular feature, LiBTBB yielded sufficiently high ionic conductivity solutions, and exhibited wide electrochemical stability windows $4.1 \mathrm{~V}$ vs. $\mathrm{Li} / \mathrm{Li}^{+}[41,42,137]$.

\subsection{Lithium bis $\left[2,2^{\prime}\right.$-naphthalenediolato (2-)-O, $\left.\mathrm{O}^{\prime}\right]$ borate (LiBNB)}

LiBNB has two naphthalene chelating groups with even bigger molecular weight of 334.1 Da (shown in Scheme 4). Compared with LiBBB, it has a higher decomposition temperature up to $320^{\circ} \mathrm{C}$ and lower solubility in carbonate solvents.

LiBNB was made from commercially available 2,3dihydroxynaphthylene, boric acid, and lithium hydroxide. The scheme of its synthesis was depicted in Eq. (17) [41].

$2 \mathrm{C}_{10} \mathrm{H}_{8} \mathrm{O}_{2}+\mathrm{B}(\mathrm{OH})_{3}+\mathrm{LiOH} \rightarrow \mathrm{Li}\left[\mathrm{B}\left(\mathrm{O}_{2} \mathrm{C}_{10} \mathrm{H}_{6}\right)_{2}\right]+4 \mathrm{H}_{2} \mathrm{O}$

LiBNB had a large molecular weight of anion, so the viscosity of LiBNB electrolyte was considerably higher than that of LiBBB electrolyte. However, the conductivity of LiBNB electrolytes was comparable to that of LiBBB [136]. Moreover, when compared with those cells using traditional electrolytes, such as LiPF $_{6}$ and $\mathrm{LiClO}_{4}$-based electrolytes, the cell using LiBNB-electrolyte delivered moderate discharge capacities. The efficiency of the LiBNB electrolyte after long cycling was nearly equal to that of the $\mathrm{LiPF}_{6}$ and $\mathrm{LiClO}_{4}$-based electrolytes. However, its electrochemical window was only to $3.8 \mathrm{~V} \mathrm{vs}$. $\mathrm{Li} / \mathrm{Li}^{+}$in $\mathrm{EC} / \mathrm{DMC}$, which hindered its future application in lithium ion batteries [42].

\subsection{Lithium bis(salicylate-2-) borate (LiBSB)}

Lithium bis(salicylate-2-) borate possesses two salicylato chelating groups with the molecular weight of 290.0 Da (shown in Scheme 4). The decomposition reaction of LiBSB will occur at $290^{\circ} \mathrm{C}$. Its solubility can reach $1.3 \mathrm{M}$ in carbonate solvents. LiBSB was obtained by the direct reaction of lithium hydroxide, boric acid and the bidentate ligand salicylic acid in water according to Eq. (19) [42].

$\mathrm{LiOH}+\mathrm{B}(\mathrm{OH})_{3}+2 \mathrm{C}_{7} \mathrm{H}_{6} \mathrm{O}_{3} \rightarrow \mathrm{LiB}\left(\mathrm{C}_{7} \mathrm{H}_{4} \mathrm{O}_{3}\right)_{2}+4 \mathrm{H}_{2} \mathrm{O}$
As salicylato group had a lower oxidation potential value than oxalate group, LiBSB possesses a comparatively lower oxidation potential than LiBOB [26]. The CV studies of $\mathrm{LiMn}_{2} \mathrm{O}_{4}$ in LiBSBelectrolyte showed that bis(salicylato)borate anions underwent irreversible oxidation between $4.5 \mathrm{~V}$ vs. $\mathrm{Li} / \mathrm{Li}^{+}$and resulted in the formation of passivating surface films. The calculated HOMO and LUMO of the $\mathrm{BSB}^{-}$anion are presented in Fig. 9. Both HOMO and LUMO were mainly located at one of the salicylato groups, although some contribution of the other group could be detected, especially in the case of the radical. The cells using LiBSB-electrolyte exhibited a high efficiency for a long cycling, despite the lower ion conductivity than that of LiBBB or LiBNB [138]. So, as lithium salt for lithium ion battery, LiBSB might process a promising prospect in low voltage batteries. However, many fundamentals such as ionic conductivity and transference numbers and electrode compatibility are still no clear yet.

\subsection{Lithium bis $\left[2,2^{\prime}\right.$-biphenyldiolato (2-)-O, $\left.O^{\prime}\right]$ borate (LiBBPB)}

LiBBPB possesses two large biphenyl chelating groups with much larger molecular weight of 386.1 Da (shown in Scheme 4). It has a very high decomposition temperature up to $370^{\circ} \mathrm{C}$ but poor solubility in carbonate solvents.

LiBBPB was obtained by the replacement of methoxy ligands of lithium tetramethanolatoborate by the bidentate ligand 2,2' dihydroxybiphenyl in acetonitrile according to Eq. (20) [42].

$\mathrm{LiB}\left(\mathrm{OCH}_{3}\right)_{4}+2 \mathrm{C}_{12} \mathrm{H}_{8}(\mathrm{OH})_{2} \stackrel{\mathrm{CH}_{3} \mathrm{CN}_{2}}{\longrightarrow} \mathrm{LiBBPB}+4 \mathrm{CH}_{3} \mathrm{OH}$

It was well known that biphenyl had higher conjugate energy than benzene and naphthalene. The LiBBPB exhibited a better thermal stability compared with that of LiBBB and LiBNB $[136,137]$. In addition, LiBBPB had a high electrochemical stability for oxidation, which could be up to $4.1 \mathrm{~V}$ vs. $\mathrm{Li} / \mathrm{Li}^{+}$. Furthermore, LBBPB electrolyte possessed a higher cycling efficiency than that of $\mathrm{LiPF}_{6}$. These excellent performances deserve further investigation.

However, it was difficult for LBBPB to dissolve in PC/DMC or EC/DME solvents [136], which resulted in a low ion conductivity. So, it is imperative to explore a strategy to improve solubility of LiBBPB in liquid solvents.

\subsection{Lithium [1,2-benzenediolato(2-)-O,O' oxalato] borate (LiBDOB)}

LiBDOB possesses one pyrocatechol- and one oxalate-chelating groups (shown in Scheme 4). LiBDOB has the combined chemical structures of LiBBB and LiBOB and its molecular weight is 213.7 Da. LiBDOB has a decomposition temperature at $256^{\circ} \mathrm{C}$. However, its solubility in carbonates is much lower than both LiBBB 
a)

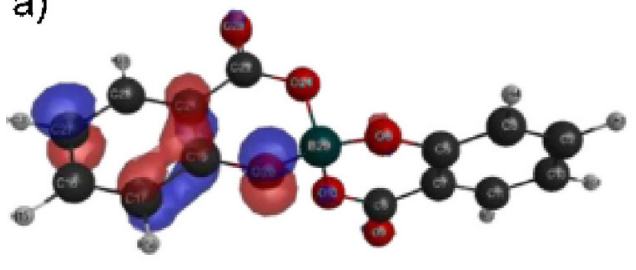

b)

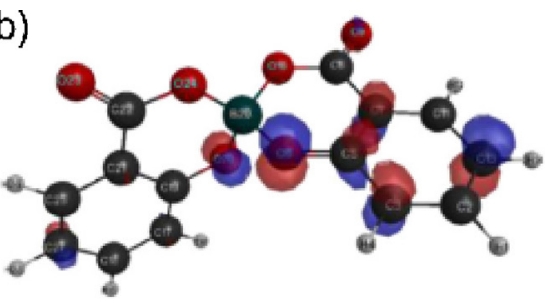

Fig. 9. Bis(salicylato) borate (BSB-), structure and orbital shape of the (a) BSB ${ }^{-}$anion with HOMO and (b) BSB ${ }^{-}$radical with $\mathrm{LUMO}^{-}$ Reprinted from Ref. [26], Copyright (2013), with permission from Elsevier.

and LiBOB. LiBDOB was synthesized according to Eq. (21) reported by Xue [143].

$\mathrm{C}_{2} \mathrm{H}_{2} \mathrm{O}_{4}+\mathrm{C}_{6} \mathrm{H}_{6} \mathrm{O}_{2}+\mathrm{H}_{3} \mathrm{BO}_{3}+\frac{1}{2} \mathrm{Li}_{2} \mathrm{CO}_{3} \rightarrow \mathrm{LiBDOB}+\frac{7}{2} \mathrm{H}_{2} \mathrm{O}+\frac{1}{2} \mathrm{CO}_{2}$

As can be seen from Scheme 4, the $\mathrm{BDOB}^{-}$has asymmetrical structure with benzenediolato and oxalato complexes of boron. Its thermal, electrochemical stabilities and conductivities were studied and compared with those of LiBBB and LiBOB electrolytes by Xue et al. [143]. Combination of these two moieties endows it with a synergistic property of LiBBB and LiBOB [140]. For example, comparing the ionic conductivities of LiBDOB solutions in different solvents with those of LiBBB and LiBOB, it was observed that LiBDOB solutions with the same concentration possessed higher ionic conductivities than those of LiBBB, but lower than LiBOB solutions. Its electrochemical oxidation potential was a bit higher than those of LiBBB in the same organic solvents used in batteries, but lower than those of LiBOB.

\subsection{Lithium salicylato-oxalato borate (LiSOB)}

Similar to LiBDOB, the chemical structure of LiSOB is also asymmetric. It combines one oxalate- and one salicilato-chelating groups (shown in Scheme 5).

The synthesis process of LiSOB had been reported by Dietz et al. [144]. Suitable solvents were chosen to form an azeotrope with water, for example, saturated or aromatic solvents such as heptane, octane, toluene or cumene.

$$
\begin{aligned}
& \mathrm{C}_{2} \mathrm{H}_{2} \mathrm{O}_{4}+\mathrm{C}_{7} \mathrm{H}_{6} \mathrm{O}_{3}+\mathrm{H}_{3} \mathrm{BO}_{3}+\mathrm{LiOH} \rightarrow \mathrm{LiSOB}+4 \mathrm{H}_{2} \mathrm{O} \\
& \mathrm{C}_{2} \mathrm{H}_{2} \mathrm{O}_{4}+\mathrm{C}_{7} \mathrm{H}_{6} \mathrm{O}_{3}+\mathrm{H}_{3} \mathrm{BO}_{3}+\frac{1}{2} \mathrm{Li}_{2} \mathrm{CO}_{3} \rightarrow \mathrm{LiSOB}+\frac{7}{2} \mathrm{H}_{2} \mathrm{O}+\frac{1}{2} \mathrm{CO}_{2}
\end{aligned}
$$

LiSOB was explored as an additive used in lithium ion batteries $[26,89]$. As can be seen from Scheme $5, \mathrm{SOB}^{-}$has two different chelating agents, which are oxalato ligand and salicylato ligand. So, LiSOB-electrolyte should show a combined electrochemical behavior of LiBOB and LiBSB. It displayed two reduction signals at $1.60 \mathrm{~V}$ and $1.02 \mathrm{Vvs}$. $\mathrm{Li} / \mathrm{Li}^{+}$on the graphite electrode [26,89]. Two oxidation peaks were observed at $4.51 \mathrm{~V}$ and $4.75 \mathrm{~V}$ vs. $\mathrm{Li} / \mathrm{Li}^{+}$in CV curves of LiMn ${ }_{2} \mathrm{O}_{4}$ electrodes cycled in $1 \mathrm{M} \mathrm{LiPF}_{6} / \mathrm{EC}$ :DMC with $0.1 \mathrm{M} \mathrm{LiSOB}$ at a scan rate of $0.1 \mathrm{mV} \mathrm{s}^{-1}$. However, how LiSOB affected the battery performance was unknown yet.

\subsection{Tris(pentafluorophenyl) borane (TPFPB)}

Tris(pentafluorophenyl) borane is a white, volatile solid. The molecule consists of three pentafluorophenyl groups attached in

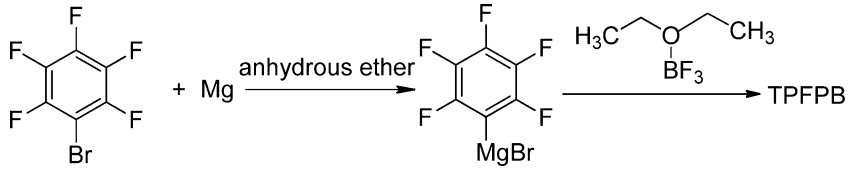

Scheme 6. The illustrative procedure for TPFPB synthesis.

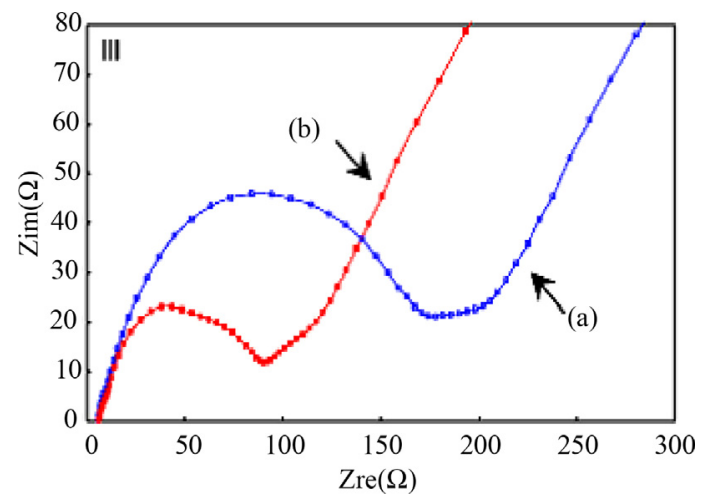

Fig. 10. Impedance spectra comparison of fully charged $\mathrm{LiFePO}_{4}$ electrodes after 100 cycles at $1.0 \mathrm{C}$ charge/discharge rate at $60^{\circ} \mathrm{C}$ in $1.2 \mathrm{M} \mathrm{LiPF}_{6} \mathrm{EC} / \mathrm{DMC}(1: 1)$ solution (a) without and (b) with $0.028 \mathrm{M}$ TPFPB. Frequency range: $0.01 \mathrm{~Hz}$ and $10^{6} \mathrm{~Hz}$. Reprinted from Ref. [147], Copyright (2009), with permission from Elsevier.

a "paddle-wheel" manner to a central boron atom; the $\mathrm{BC}_{3}$ core is planar (shown in Scheme 5). It possesses a large molecular weight of $511.9 \mathrm{Da}$ and melts at the temperature of $121^{\circ} \mathrm{C}$.

TPFPB is a kind of the anion receptors and has been developed as an additive in electrolytes for increasing the dissociation of $\mathrm{LiPF}_{6}$ in electrolytes and improving the cycle life and power capabilities of the batteries. The scheme of its synthesis was reported by Lee et al. and illustrated in Scheme 6 [145].

As an additive in $\mathrm{LiPF}_{6}$-based electrolyte, TPFPB possesses the ability of improving the cycling performance of $\mathrm{LiFePO}_{4}$ cathode at elevated temperatures [146,147]. According to the reported results, TPFPB was believed to participate in the formation of passivation films on $\mathrm{LiFePO}_{4}$ electrode surface and in the dissolution of $\mathrm{LiF}$ in the films, which resulted in the improved lithium ion conductivity and better cell performance (shown in Fig. 10). Similarly, the power capabilities of graphite/ $\mathrm{Li}_{1.1}\left[\mathrm{Ni}_{1 / 3} \mathrm{Co}_{1 / 3} \mathrm{Mn}_{1 / 3}\right]_{0.9} \mathrm{O}_{2}$ cells was significantly improved when TPFPB adapted as a electrolyte additive [148].

In addition, TPFPB additive was also reported as an anion receptor for an enhanced thermal stability of the graphite anode interface in a Li-ion battery [149]. The addition of $0.2 \mathrm{M} \mathrm{TPFPB}$ to a $0.8 \mathrm{M} \mathrm{LiBF}_{4}$ EC:DEC electrolyte improved the cycling performance owing to the enhanced stability of the graphite anode interphase. The onset temperature of the first exothermic reaction for a graphite anode cycled in above electrolyte increased from $60^{\circ} \mathrm{C}$ to $140-160^{\circ} \mathrm{C}$. The formed 
SEI layer contained less LiF and more solvent-based reduction products.

\section{Single-ion dominantly conducting polyborates}

A dissociated lithium ion in the liquid electrolyte is usually solvated with four to six solvent molecules to form $\mathrm{Li}^{+}$solvation sheath [150], whose size is relatively larger than those of the anion, which hampers its rapid transportation. In general, the conventional liquid electrolytes behave as an anion-dominant conductor with the anion transfer number of about 0.67 and the cation counterpart of about 0.33 . As the electrodes' reactions only exchange lithium ion with the electrolyte, the anion overconcentration often occurs and increases the polarization. In addition, the over-concentrated anions will participate in undesirable side reactions at the surfaces of electrodes, which also can directly affect the resistance and impedance of batteries. Therefore it is important to increase $\mathrm{Li}^{+}$ion transference number $\left(t_{+}\right)$to gain less polarization for lithium ion batteries [151].

There are two strategies to achieve the single ion conductors. The first one is to introduce interacting sites that preferentially interact with the anions [145,152]. The other is to anchor anions to the polymer backbone, which is the most effective method to achieve single-ion conductors [153]. Many singleion-conductive polymer electrolytes, based on polyethyleneimine, polyphosphazene, and polysiloxane backbones were synthesized [154-157]. Florjanczyk et al. reported significant transference number enhancements by incorporating $\mathrm{BF}_{3}$, which is coordinated with the carboxylate anions of the polymer network [157]. Tsutsumi and coworkers reported a single-ion siloxane SPE with $\sigma_{\text {bulk }}$ of $7 \times 10^{-7} \mathrm{Scm}^{-1}$ and $t_{+}$of 0.98 at room temperature [156]. New single lithium-ion conducting polymer electrolytes are prepared by Prof. Zhou via a copolymerization of two monomers, lithium (4-styrenesulfonyl)(trifluoromethanesulfonyl)imide (LiSTFSI) and methoxy-polyethylene glycol acrylate (MPEGA, $\left.\mathrm{CH}_{2} \mathrm{CHCO}_{2}\left(\mathrm{CH}_{2} \mathrm{CH}_{2} \mathrm{O}\right)_{n} \mathrm{CH}_{3}, n=8\right)$. The solid-state ionic conductivities of the Li[PSTFSI-co-MPEGA] copolymer electrolytes were $7.6 \times 10^{-6} \mathrm{Scm}^{-1}$ at $25^{\circ} \mathrm{C}$ and reached $10^{-4} \mathrm{~S} \mathrm{~cm}^{-1}$ at $60^{\circ} \mathrm{C}$ [158]. Moreover, Armand reported a P(STFSILi)-PEO-P(STFSILi) material as a polymer electrolyte exhibiting unprecedented levels of performance for lithium-metal batteries in terms of ionic conductivity of dry single-ion polymer electrolytes, transport number (>0.85) and improved mechanical strength $[159,160]$.

Very recently, several single-ion conducting polymeric lithium borate salts, including lithium poly[oligo(ethylene glycol) oxalate borate] (LiPEGOB), lithium polyvinyl alcohol oxalate borate (LiPVAOB), lithium polyacrylic acid oxalate borate (LiPAAOB), lithium polymeric tartaric acid borate (LiPTB) and some lithium aromatic polyborates (e.g. LiPAB), were developed and demonstrated to be very promising application in lithium ion batteries $[100,109,161-165]$.

\subsection{Lithium poly[oligo(ethylene glycol) oxalate borate] (LiPEGOB)}

Novel polyanionic solid electrolytes with weak coulomb traps and controllable caps and spacers such as lithium poly[oligo(ethylene glycol) oxalate borate] (LiPEGOB), lithium poly[oligo(ethylene glycol) malonato borate] (LiPEGMB) and lithium poly[oligo(propylene glycol) oxalate borate] (LiPPGOB) were developed by Prof. Angell, which are shown in Scheme 7. The synthetic routes of LiPEGOB are presented as follows [166-168].

$\mathrm{LiOH}+\mathrm{H}_{2} \mathrm{C}_{2} \mathrm{O}_{4}+\mathrm{B}(\mathrm{OH})_{3} \rightarrow \mathrm{LiB}\left(\mathrm{C}_{2} \mathrm{O}_{4}\right)(\mathrm{OH})_{2}+2 \mathrm{H}_{2} \mathrm{O}$

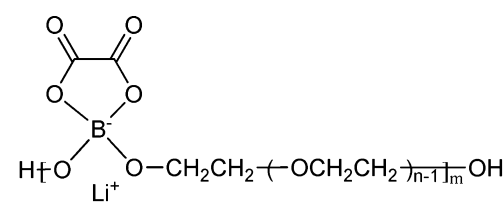

LiPEGOB<smiles>CC(C)C(C)OCO[B-]1([O-])OC(=O)C(=O)O1</smiles>

LiPPGOB<smiles>O=C1CC(=O)O[B-]([TeH])(OCCCOCCCCO)O1</smiles><smiles>CCC1CC(C)O[B-]2(OC(=O)C(=O)O2)OC1=O</smiles>

LiPEGMB LiPVAOB<smiles>CC1CC2CC(CC3CC3)C(=O)O[B-]3(CC(O2)C(C)O3)OC1C</smiles><smiles>C[B-]1(C)OC(=O)C2O[B-]3(OC(=O)C2O1)OC(=O)C1O[B-](C)(C)OC(=O)C1O3</smiles>

LiPAAOB LiPTB

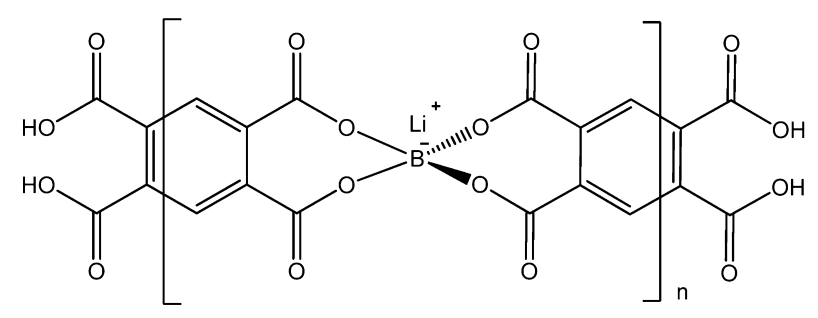

LiPAB

Scheme 7. Structural formulae of single-ion conducting polyborates.

$\mathrm{mLiB}\left(\mathrm{C}_{2} \mathrm{O}_{4}\right)(\mathrm{OH})_{2}+\mathrm{mHO}\left(\mathrm{CH}_{2} \mathrm{CH}_{2} \mathrm{O}\right)_{n} \mathrm{H} \rightarrow$ LiPEGOB $+2 \mathrm{mH}_{2} \mathrm{O}$

The LiPEGMB and LiPPGOB could be synthesized using the similar procedure. Among these polyanionic solid electrolytes, the boron was strongly chelated by the oxygen groups in the polymer chain. Thus, the ionic conduction in polymer electrolytes is dominated by the motion of the cations. For LiPEGOB, with increase of spacer repeating units from $n=3$ to $n=23$, glass transition temperature decreases from $-0.9^{\circ} \mathrm{C}$ to $-63.1^{\circ} \mathrm{C}$ [166]. That meant the introduction of mono-diacyl-capped orthoborate moieties into the polymer $(n=23)$ did not affect the flexibility of the polymer chain, making sure that LiPEGOB still kept solid phase at ambient temperature. Furthermore, the maximum conductivity of LiPEGOB was as high as $10^{-5} \mathrm{~S} \mathrm{~cm}^{-1}$ at room temperature. Another excellent electrochemical performance for LiPEGOB was that it had a good electrochemical stability of up to $4.5 \mathrm{~V} \mathrm{vs}$. $\mathrm{Li}^{+} / \mathrm{Li}$. The drawback of 

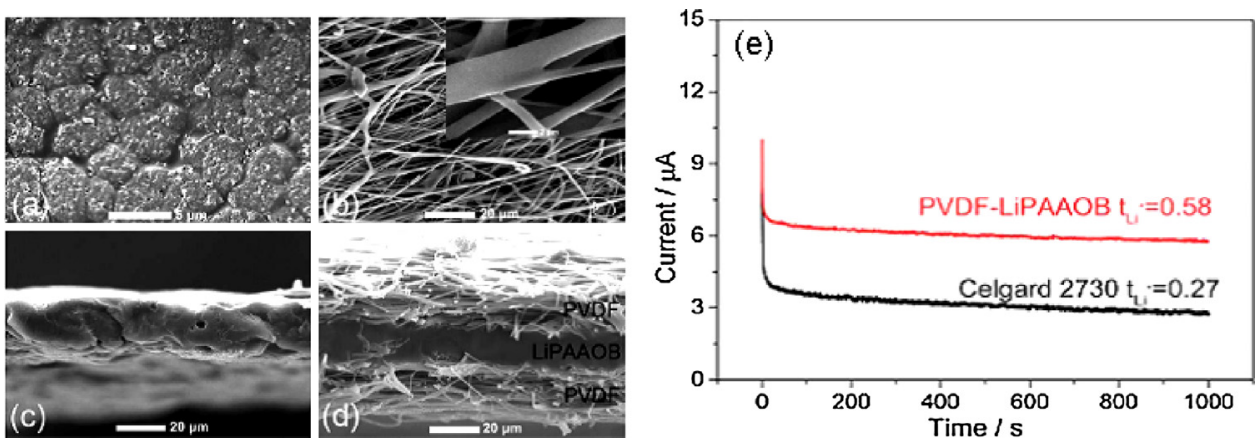

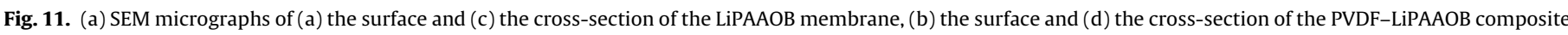

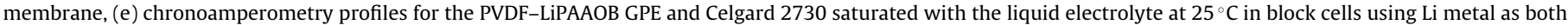
electrodes with a step potential of $10 \mathrm{mV}$.

Reproduced from Ref. [163], with permission of The Royal Society of Chemistry.

these materials was that they unavoidably contained some LiBOB as a side-product in the synthetic process, which lower the lithium ion transport number to be much less than 1.0.

\subsection{Lithium polyvinyl alcohol oxalate borate (LiPVAOB) and lithium polyacrylic acid oxalate borate (LiPAAOB)}

Recently, Wu et al. developed lithium polyvinyl alcohol oxalate borate (LiPVAOB) and lithium polyacrylic acid oxalate borate (LiPAAOB), which were synthesized by the reaction of poly(vinyl alcohol) (PVA) or polyacrylic acid (PAA), lithium carbonate, boric acid and oxalic acid, respectively, shown in Scheme 8 [163,169]. These membranes showed good thermal properties and good morphology. After absorbing 3\% amount of PC, the LiPVAOB and LiPAAOB electrolyte membranes showed high ionic conductivity up to $6.11 \times 10^{-6} \mathrm{~S} \mathrm{~cm}^{-1}$ and $2.3 \times 10^{-6} \mathrm{~S} \mathrm{~cm}^{-1}$ respectively at

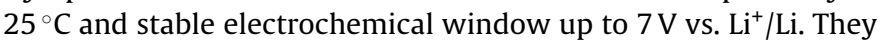
also achieved another gel polymer electrolyte by gelation a sandwiched composite membrane consisted of PVDF/LiPAAOB/PVDF with a LiPF $_{6}$ liquid electrolyte $[163,165]$. The transference number of lithium ion in this GPE $\left(t_{+}=0.58\right)$ at ambient temperature was double that in the commercial separator saturated with liquid electrolyte $\left(t_{+}=0.27\right)$, which was shown in Fig. 11 . In addition, the phenomenon of gas emission did not occur in the batteries using LiPAAOB, which greatly reduced the risk of explosion when operating at high temperature. So, the LiPAAOB electrolyte shows great

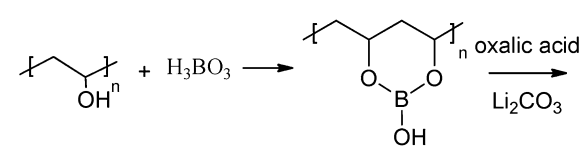

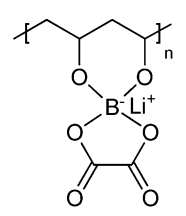

LiPVAOB

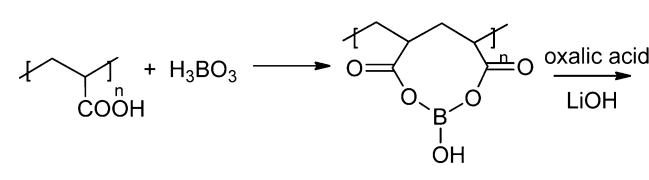<smiles>CCC1CC2CCC(O2)C(=O)O[B-]2(OC1C)OC(C)C(C)O2</smiles>

LiPAAOB

Scheme 8. The synthesis of LiPVAOB and LiPAAOB. Reprinted from Ref. [151] Copyright (2013), with permission from Elsevier. Reprinted from Ref. [169], Copyright (2012), with permission from Elsevier.

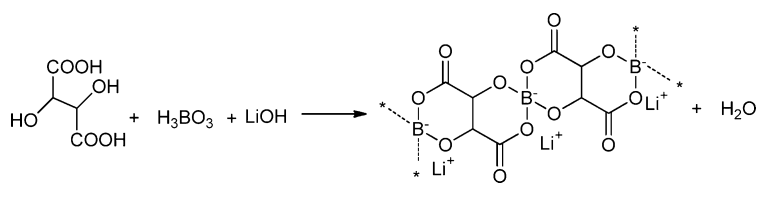

Scheme 9. The illustrate synthesis of LiPTB in an aqueous solution.

possibility for applications in the lithium ion batteries requiring high power and high safety.

\subsection{Lithium polymeric tartaric acid borate (LiPTB)}

Very recently, Cui and his coworker synthesized lithium polymeric tartaric acid borate (LiPTB) via a one-step reaction in aqueous solution, which was shown in Scheme 9 [161,162]. The LiPTB has unique structure incorporating the $\mathrm{BOB}^{-}$building blocks in the main polymeric chains not by the side chains. LiPTB possesses a high decomposition temperature at $330^{\circ} \mathrm{C}$, which is potential for improving the battery safety characteristic (shown in Fig. 12(a)) [161,162].

The polymeric electrolyte of LiPTB@PVdF-HFP was developed by a doctor-blading process followed by a soaking process in PC [161] or EC/DMC [162]. Its surface SEM image was shown in Fig. 12(b). This membrane exhibited considerable ionic conductivity, high lithium ion transference number $\left(t_{\mathrm{Li}^{+}}=0.93\right)$ and high anodic electrochemical stability (4.7 V vs. $\mathrm{Li}^{+} / \mathrm{Li}$ ) at $80^{\circ} \mathrm{C}$ (shown in Fig. 13). The $\mathrm{LiFePO}_{4} / \mathrm{Li}$ batteries using PC swollen LiPTB@PVDF-HFP membrane exhibit stable charge/discharge behavior, preferable rate capability and satisfactory cycling performance at $80^{\circ} \mathrm{C}$. The superior high temperature performance of PC swollen LiPTB@PVDF-HFP could endow this kind of polymer electrolyte a very promising application for power battery of electric vehicle normally operating at relatively high temperature.

In addition, the EC/DMC swollen LiPTB@PVDF-HFP exhibited a superior lithium ionic conductivity at ambient temperature $\left(\sigma_{\mathrm{Li}^{+}}=0.45 \mathrm{mS} \mathrm{cm}^{-1}\right)$ and significantly high lithium ion transference number $\left(t_{\mathrm{Li}+}=0.91\right)$, which was presented in Table 3 . This gel electrolyte was further discovered to remarkably improve

Table 3

Apparent ionic conductivity comparison for both electrolyte systems.

\begin{tabular}{llll}
\hline Samples & $\sigma\left(\mathrm{mScm}^{-1}\right)$ & $t_{\mathrm{Li}+}$ & $\sigma_{\mathrm{Li}+}\left(\mathrm{mS} \mathrm{cm}^{-1}\right)$ \\
\hline $1 \mathrm{M} \mathrm{LiPF}_{6}$-EC/DMC (with separator) & 0.85 & 0.32 & 0.27 \\
EC/DMC swollen LiPTB@PVDF-HFP & 0.50 & 0.91 & 0.45 \\
\hline
\end{tabular}

Reprinted from Ref. [162], Copyright (2014), with permission from Elsevier. 
(a)

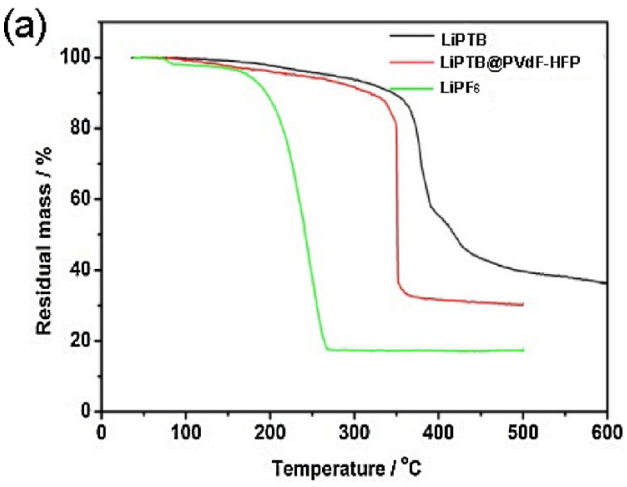

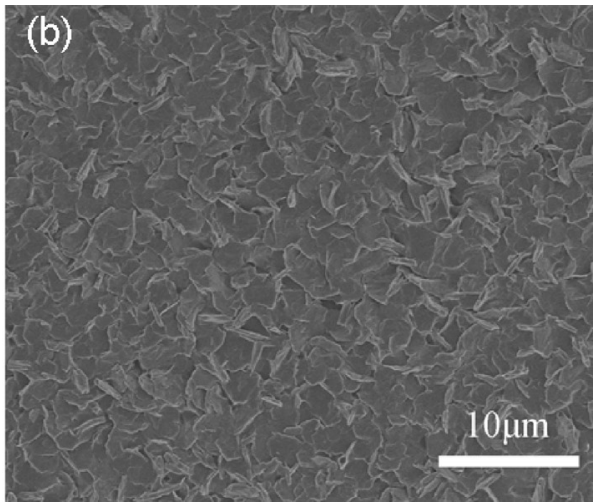

Fig. 12. (a) Thermal gravimetric analysis curves of LiPTB, LiPTB@PVDF-HFP and LiPF . (b) SEM image of LiPTB@PVDF-HFP membrane (LiPTB/PVDF-HFP=1/1 (w/w)). (a) Reprinted from Ref. [100], Copyright (2014), with permission from Elsevier. (b) Reprinted from Ref. [162], Copyright (2014), with permission from Elsevier.

(a)

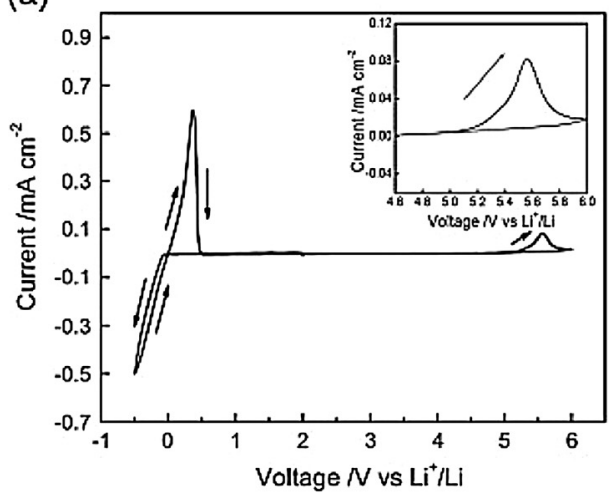

(b)

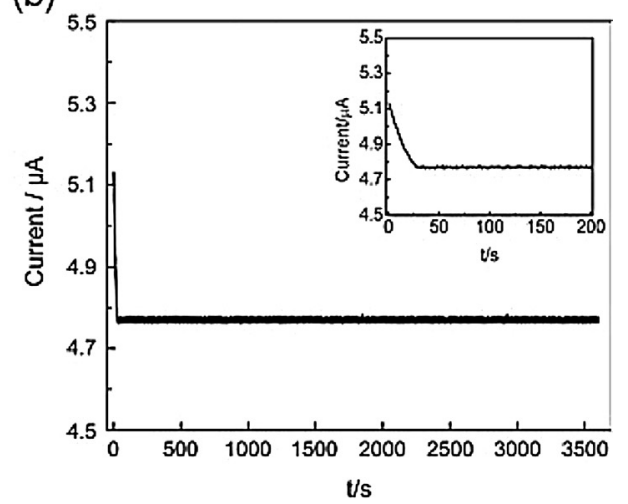

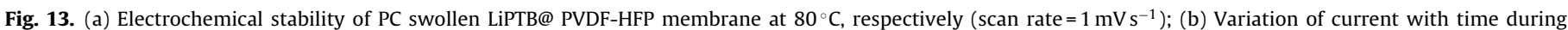

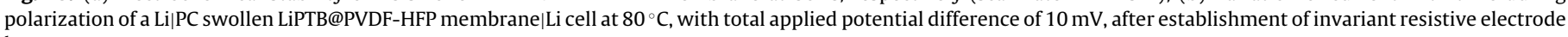
layer.

Reprinted from Ref. [162], Copyright (2014), with permission from Elsevier.

(a)

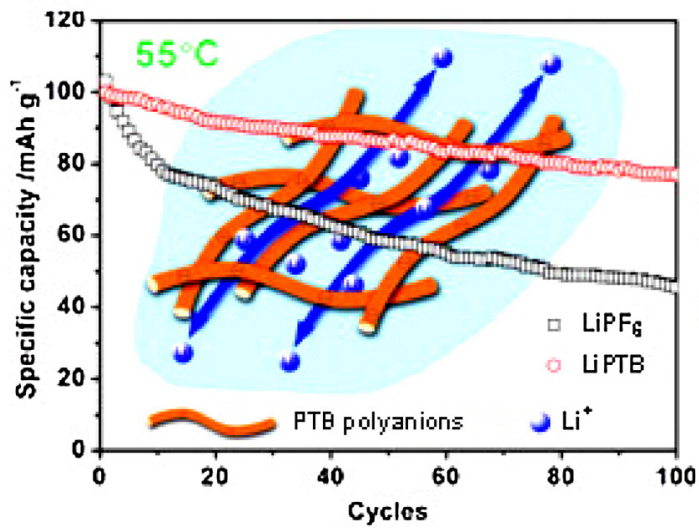

(b)

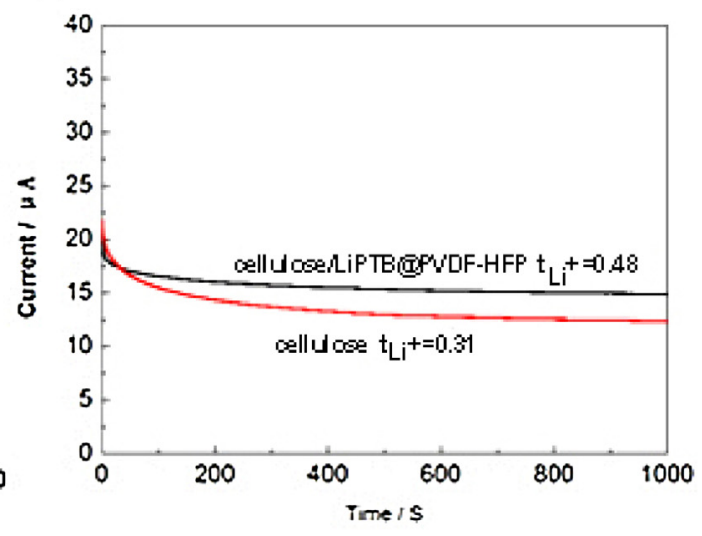

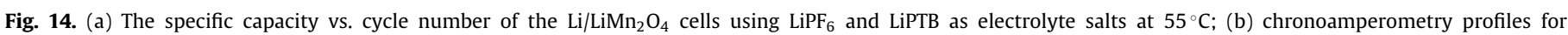
cellulose/LiPTB@PVDF-HFP separator and cellulose separator.

Reprinted from Ref. [100], Copyright (2014), with permission from Elsevier.

the cycling performance of the $\mathrm{LiMn}_{2} \mathrm{O}_{4}$ based lithium battery at elevated temperatures owing to superior thermal stability and comparable ionic conductivity (Fig. 14(a)) [100]. The dissolution of metallic $\mathrm{Mn}$ in this electrolyte was significantly suppressed than that of $\mathrm{LiPF}_{6}$ electrolyte. Moreover, the LiPTB@PVDF-HFP coated cellulose separator was evaluated to have a higher lithium ion transference number than the pristine separator (unpublished data, shown in Fig. 14(b)).

\subsection{Lithium polymeric aromatic borates (LiPAB)}

Some lithium polymeric aromatic borates had been also developed by Prof. Cheng et al. [164], one of which is shown in Scheme 10. These materials exhibited good thermal and electrochemical stability, which may be suitable for applications in Li-ion batteries as electrolytes. Their ionic conductivity was comparable to the conventional liquid electrolytes. Unlike the small molecules of 
<smiles>CCOC(=O)c1cc2c(=O)oc3c(cc-2c1C(=O)OCC)C(=O)OCCC3</smiles>

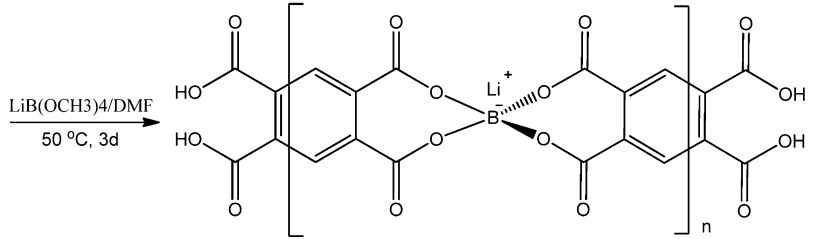

Scheme 10. Synthetic procedure of the lithium polymeric aromatic borate (LiPAB). Reproduced from Ref. [164] with permission of The Royal Society of Chemistry.

aromatic lithium salts described above, these lithium polymeric aromatic borates possessed relatively higher anodic oxidization stability due to double electro-withdrawing effect of the $\mathrm{sp}^{3}$ boron atoms. After all, these lithium polymeric aromatic borates still have relatively lower electrochemical stability than the non-aromatic borates, which may limit their potential application in high voltage lithium batteries.

\section{Perspective}

In conclusion, post lithium ion batteries need to develop green, low cost and high performance battery systems with compatible electrolytes. Lithium borate salts have been demonstrated to possess unique properties such as excellent thermal stability, comparable ionic conductivity, cost-effectiveness, environmental benignity and SEI forming properties. These properties would meet the requirement of the higher energy batteries using the $\mathrm{Si} / \mathrm{C}$ composite anode, lithium metal anode, high voltage cathodes or semi-solid lithium flowable electrodes and improved cycling performance and safety characteristics. Especially, the newly developed single-ion dominantly conducting polyborate electrolytes could be very promising electrolytes in next generation lithium ion batteries.

Some researchers have studied the $\mathrm{LiBOB}$ and $\mathrm{LiB}(\mathrm{CN})_{4}$ based electrolytes in the $\mathrm{Li}-\mathrm{O}_{2}$ batteries and found that this salts encountered serious irreversible decomposition reaction in this electrolyte system [86,170-172]. It was also reported that the $\mathrm{LiBF}_{4}$ and LiBOB-based electrolytes were not suitable to be used in Li-S batteries because they could irreversibly react with the polysulfide [173]. However, the borate-based electrolytes would exhibit a very promising prospect in the newly developed energy storage batteries such as lithium rechargeable flow batteries and sodium ion batteries. As another very promising candidate for a largescale energy storage application, the recently developed semi-solid lithium rechargeable flow battery delivers higher energy density with lower material and manufacturing cost than the conventional lithium battery. In regards to this large-scale application, the borate-based electrolytes would outperform the expensive and sensitive $\mathrm{LiPF}_{6}$ to meet the requirement of cost-effectiveness, environmental benignity as well as safety [6]. Sodium ion batteries are also attracting intensive interests as a low cost energy storage device in very recent years. The sodium bis(oxalate) borate (NaBOB) possessed high ionic conductivity up to $1.11 \times 10^{-3} \mathrm{~S} \mathrm{~cm}^{-1}$ ( $0.25 \mathrm{~mol} \mathrm{~L}^{-1}$ in DMF). Like LiBOB, NaBOB also processed excellent thermal stability at high temperature when compared to the $\mathrm{NaPF}_{6}$, which would be favorable to improve battery cycling performance especially at elevated temperatures [174]. In terms of sodium borate salts, deep insights and more investigation are needed on the SEI-forming properties and compatibilities with the sodium ion battery electrodes. So, we hope that our review provides the motivation to encourage researchers to make new attempts in this promising field.

\section{Acknowledgments}

The authors gratefully acknowledge the financial support of this work by National Natural Science Foundation of China (Grant No. 21344003), Strategic Priority Research Program of the Chinese Academy of Sciences (Grant No. XDA09010105), Natural Science Foundation of Shandong Province (Grant No. ZR2013FZ2001) and Key Technology Research Projects of Qingdao (Grant No. 12-4-124-gx and 13-4-1-10-gx).

\section{Appendix A. Supplementary data}

Supplementary data associated with this article can be found, in the online version, at http://dx.doi.org/10.1016/j.ccr.2015.02.011.

\section{References}

[1] J.M. Tarascon, M. Armand, Nature 414 (2001) 359-367.

[2] B. Scrosati, Electrochim. Acta 45 (2000) 2461-2466.

[3] M. Wakihara, Mater. Sci. Eng. Rep. 33 (2001) 109-134.

[4] B. Scrosati, J. Garche, J. Power Sources 195 (2010) 2419-2430.

[5] K. Xu, Chem. Rev. 104 (2004) 4303-4417.

[6] M. Duduta, B. Ho, V.C. Wood, P. Limthongkul, V.E. Brunini, W.C. Carter, Y.M. Chiang, Adv. Eng. Mater. 1 (2011) 511-516.

[7] G.E. Blomgren, J. Power Sources 119 (2003) 326-329.

[8] S.S. Zhang, J. Power Sources 162 (2006) 1379-1394.

[9] M. Armand, F. Endres, D.R. MacFarlane, H. Ohno, B. Scrosati, Nat. Mater. 8 (2009) 621-629.

[10] J. Barthel, M. Wühr, R. Buestrich, H.J. Gores, J. Electrochem. Soc. 142 (1995) $2527-2531$

[11] A. Caballero, M. Cruz, L. Hernan, M. Melero, J. Morales, E.R.g. Castellón, J. Electrochem. Soc. 152 (2005) A552-A559.

[12] M.k. Jo, Y.K. Lee, K.M. Kim, J. Cho, J. Electrochem. Soc. 157 (2010) A841-A845

[13] J. Arrebola, A. Caballero, L. Hernan, J. Morales, E.R. Castellón, J.R. Barrado, J. Electrochem. Soc. 154 (2007) A178-A184.

[14] N.S. Choi, J.T. Yeon, Y.W. Lee, J.G. Han, K.T. Lee, S.S. Kim, Solid State Ionics 219 (2012) 41-48.

[15] T. Kawamura, S. Okada, J. Yamaki, J. Power Sources 156 (2006) 547-554.

[16] A. Laheäär, H. Kurig, A. Jänes, E. Lust, Electrochim. Acta 54 (2009) 4587-4594

[17] S.F. Lux, I.T. Lucas, E. Pollak, S. Passerini, M. Winter, R. Kostecki, Electrochem. Commun. 14 (2012) 47-50.

[18] K. Sato, L.W.Zhao, S. Okada, J. Yamaki, J. Power Sources 196 (2011) 5617-5622

[19] L. Wang, Y. Huang, D. Jia, Solid State Ionics 177 (2006) 1477-1481.

[20] S. Wilken, P. Johansson, P. Jacobsson, Solid State Ionics 225 (2012) 608-610.

[21] D.P. Abraham, M.M. Furczon, S.H. Kang, D.W. Dees, A.N. Jansen, J. Power Sources 180 (2008) 612-620.

[22] Y. Kusachi, Z. Zhang, J. Dong, K. Amine, J. Phys. Chem. C 115 (2011) 24013-24020.

[23] K. Xu, S. Zhang, T.R. Jow, W. Xu, C.A. Angell, Electrochem. Solid-State Lett. 5 (2002) A26-A29.

[24] Z.H. Chen, Y. Qin, J. Liu, K. Amine, Electrochem. Solid-State Lett. 12 (2009) A69-A72.

[25] J. Li, K. Xie, Y.Q. Lai, Z.A. Zhang, F.Q. Li, X. Hao, X.J. Chen, Y.X. Liu, J. Power Sources 195 (2010) 5344-5350.

[26] S. Kaymaksiz, F. Wilhelm, M. Wachtler, M. Wohlfahrt-Mehrens, C. Hartnig, I. Tschernych, U. Wietelmann, J. Power Sources 239 (2013) 659-669.

[27] T. Eriksson, A. Andersson, C. Gejke, T. Gustafsson, J.O. Thomas, Langmuir 18 (2002) 3609-3619.

[28] A. Chagnes, J. Swiatowska, Lithium Ion Batteries - New Developments, Intechopen, 2012, pp. 145-172, http://cdn.intechopen.com/pdfs-wm/29286.pdf

[29] E. Peled, C. Menachem, D. Bar Tow, A. Melman, J. Electrochem. Soc. 143 (1996) L4-L7.

[30] J.Y. Song, Y.Y. Wang, C.C. Wan, J. Power Sources 77 (1999) 183-197.

[31] G.H. Wrodnigg, J.O. Besenhard, M. Winter, J. Electrochem. Soc. 146 (1999) $470-472$.

[32] J. Yang, Y. Takeda, N. Imanishi, O. Yamamoto, J. Electrochem. Soc. 146 (1999) 4009-4013.

[33] S.S. Zhang, K. Xu, T.R. Jow, J. Electrochem. Soc. 149 (2002) A586-A590.

[34] N.N. Greenwood, A. Earnshaw, Chemistry of the Elements, 2nd ed., Butterworth-Heinemann, Oxford, 1997.

[35] V. Aravindan, J. Gnanaraj, S. Madhavi, H.K. Liu, Chem. Eur. J. 17 (2011) $14326-14346$.

[36] P.V. Wright, Electrochim. Acta 43 (1998) 1137-1143. 
[37] V. Di Noto, S. Lavina, G.A. Giffin, E. Negro, B. Scrosati, Electrochim. Acta 57 (2011) 4-13.

[38] A. Lewandowski, M. Świderska, Agnieszka, J. Power Sources 194 (2009) 601-609.

[39] M. Amereller, T. Schedlbauer, D. Moosbauer, C. Schreiner, C. Stock, F. Wudy, S. Zugmann, H. Hammer, A. Maurer, R.M. Gschwind, H.D. Wiemhöfer, M. Winter, H.J. Gores, Prog. Solid State Chem. (2014), http://dx.doi.org/10.1016/j. progsolidstchem.2014.1004.1001.

[40] J. Barthel, R. Buestrich, E. Carl, H.J. Gores, J. Electrochem. Soc. 143 (1996) 3565-3571.

[41] J. Barthel, R. Buestrich, E. Carl, H.J. Gores, J. Electrochem. Soc. 143 (1996) 3572-3575.

[42] J. Barthel, R. Buestrich, H. Gores, M. Schmidt, M. Wühr, J. Electrochem. Soc. 144 (1997) 3866-3870.

[43] J. Barthel, A. Schmid, H.J. Gores, J. Electrochem. Soc. 147 (2000) 21-24.

[44] J. Barthel, M. Schmidt, H.J. Gores, J. Electrochem. Soc. 145 (1998) L17-L20.

[45] Y. An, P. Zuo, X. Cheng, L. Liao, G. Yin, Electrochim. Acta 56 (2011) 4841-4848.

[46] F. Azeez, P.S. Fedkiw, J. Power Sources 195 (2010) 7627-7633.

[47] Z. Chen, W.Q. Lu, J. Liu, K. Amine, Electrochim. Acta 51 (2006) 3322-3326.

[48] J. Dong, Z. Zhang, Y. Kusachi, K. Amine, J. Power Sources 196 (2011) 2255-2259.

[49] J. Huang, X. Liu, X. Kang, Z. Yu, T. Xu, W. Qiu, J. Power Sources 189 (2009) $458-461$.

[50] H. Kaneko, K. Sekine, T. Takamura, J. Power Sources 146 (2005) 142-145.

[51] M.Z. Kufian, M.F. Aziz, M.F. Shukur, A.S. Rahim, N.E. Ariffin, N.E.A. Shuhaimi, S.R. Majid, R. Yahya, A.K. Arof, Solid State Ionics 208 (2012) 36-42.

[52] D. Lee, J. Hassoun, S. Panero, Y. Sun, B. Scrosati, Electrochem. Commun. 14 (2012) 43-46.

[53] Z. Yu, T. Xu, T. Xing, L. Fan, F. Lian, W. Qiu, J. Power Sources 195 (2010) 4285-4289.

[54] J.L. Allen, S.D. Han, P.D. Boyle, W.A. Henderson, J. Power Sources 196 (2011) 9737-9742.

[55] V. Aravindan, P. Vickraman, Solid State Sci. 9 (2007) 1069-1073.

[56] Q. Wu, W. Lu, M. Miranda, T.K. Honaker-Schroeder, K.Y. Lakhsassi, D. Dees, Electrochem. Commun. 24 (2012) 78-81.

[57] M. Xu, L. Zhou, L. Hao, L. Xing, W. Li, B.L. Lucht, J. Power Sources 196 (2011) 6794-6801.

[58] S. Zugmann, D. Moosbauer, M. Amereller, C. Schreiner, F. Wudy, R. Schmitz, R. Schmitz, P. Isken, C. Dippel, R. Müller, M. Kunze, A. Lex Balducci, M. Winter, H.J. Gores, J. Power Sources 196 (2011) 1417-1424.

[59] M. Ue, S. Mori, J. Electrochem. Soc. 142 (1995) 2577-2581.

[60] M.S. Ding, T.R. Jow, J. Electrochem. Soc. 151 (2004) A2007-A2015.

[61] N. Takami, T. Ohsaki, H. Hasebe, M. Yamamoto, J. Electrochem. Soc. 149 (2002) A9-A12.

[62] D. Williams, B. Pleune, J. Kouvetakis, M.D. Williams, R.A. Andersen, J. Am. Chem. Soc. 122 (2000) 7735-7741.

[63] J. Scheers, P. Johansson, P. Jacobsson, J. Electrochem. Soc. 155 (2008) A628-A634.

[64] T. Küppers, E. Bernhardt, H. Willner, H.W. Rohm, M. Köckerling, Inorg. Chem. 44 (2005) 1015-1022.

[65] T.R. Jow, K. Xu, M.S. Ding, S.S. Zhang, J.L. Allen, K. Amine, J. Electrochem. Soc. 151 (2004) A1702-A1706.

[66] K. Xu, S.S. Zhang, U. Lee, J.L. Allen, T.R. Jow, J. Power Sources 146 (2005) 79-85.

[67] W. Xu, C.A. Angellz, Electrochem. Solid-State Lett. 4 (2001) E1-E4.

[68] K. Xu, S. Zhang, B.A. Poese, T.R. Jow, Electrochem. Solid-State Lett. 5 (2002) A259-A262.

[69] T. Schedlbauer, S. Krueger, R. Schmitz, R.W. Schmitz, C. Schreiner, H.J. Gores, S. Passerini, M. Winter, Electrochim. Acta 92 (2013) 102-107.

[70] T. Schedlbauer, U.C. Rodehorst, C. Schreiner, H.J. Gores, M. Winter, Electrochim. Acta 107 (2013) 26-32.

[71] I.A. Shkrob, Y. Zhu, T.W. Marin, D.P. Abraham, J. Phys. Chem. C 117 (2013) 23750-23756.

[72] S.S. Zhang, Electrochem. Commun. 8 (2006) 1423-1428.

[73] Y. Zhu, Y. Li, M. Bettge, D.P. Abraham, J. Electrochem. Soc. 159 (2012) A2109-A2117.

[74] Y. Matsuda, M. Morita, K. Yamada, K. Hirai, J. Electrochem. Soc. 132 (1985) 2538-2543.

[75] M. Ue, J. Electrochem. Soc. 141 (1994) 3336-3342.

[76] I. Shapiro, H.G. Weiss, J. Am. Chem. Soc. 75 (1953) 1753-1754.

[77] Y. Zhou, CN101318664 A (2008)

[78] K. Matsumoto, R. Hagiwara, Z. Mazej, E. Goreshnik, B. Žemva, J. Phys. Chem. B 110 (2006) 2138-2141.

[79] M.S. Ding, J. Chem. Eng. Data 49 (2004) 1102-1109.

[80] S. Zhang, K. Xu, T. Jow, J. Solid State Electrochem. 7 (2003) 147-151.

[81] S. Song, T.J. Richardson, G.V. Zhuang, T.M. Devine, J.W. Evans, Electrochim. Acta 49 (2004) 1483-1490.

[82] W.K. Behl, E.J. Plichta, J. Power Sources 72 (1998) 132-135.

[83] S.S. Zhang, T.R. Jow, J. Power Sources 109 (2002) 458-464.

[84] C.M. Burba, E.D. Butson, J.R. Atchley, M.S. Johnson, J. Phys. Chem. C 118 (2013) 366-375.

[85] J. Scheers, J. Pitawala, F. Thebault, J.K. Kim, J.H. Ahn, A. Matic, P. Johansson, P. Jacobsson, PCCP 13 (2011) 14953-14959.

[86] R. Younesi, M. Hahlin, M. Treskow, J. Scheers, P. Johansson, K. Edström, J. Phys. Chem. C 116 (2012) 18597-18604

[87] K. Xu, S. Zhang, R. Jow, J. Power Sources 143 (2005) 197-202.
[88] J.C. Panitz, U. Wietelmann, M. Wachtler, S. Ströbele, M. Wohlfahrt Mehrens, J. Power Sources 153 (2006) 396-401.

[89] M. Wachtler, M. Wohlfahrt Mehrens, S. Ströbele, J.C. Panitz, U. Wietelmann, J. Appl. Electrochem. 36 (2006) 1199-1206.

[90] K. Xu, S. Zhang, T.R. Jow, Electrochem. Solid-State Lett. 6 (2003) A117-A120

[91] K. Xu, U. Lee, S.S. Zhang, T.R. Jow, J. Electrochem. Soc. 151 (2004) A2106-A2112.

[92] S. Wang, W. Qiu, T. Li, B. Yu, H. Zhao, J. Electrochem. Soc. 1 (2006) 250-257.

[93] U. Lischka, U. Wietelmann, M. Wegner, DE19829030C1 (1998).

[94] K. Xu, U. Lee, S.S. Zhang, M. Wood, T.R. Jow, Electrochem. Solid-State Lett. 6 (2003) A144-A148.

[95] J. Zhang, Q. Kong, Z. Liu, S. Pang, L. Yue, J. Yao, X. Wang, G. Cui, Solid State Ionics 245-246 (2013) 49-55.

[96] F. Mestre Aizpurua, S. Hamelet, C. Masquelier, M.R. Palacín, J. Power Sources 195 (2010) 6897-6901.

[97] K. Amine, J. Liu, I. Belharouak, Electrochem. Commun. 7 (2005) 669-673.

[98] K. Xu, B. Deveney, K. Nechev, Y. Lam, T.R. Jow, J. Electrochem. Soc. 155 (2008) A959-A964.

[99] J. Jiang, J.R. Dahn, Electrochem. Commun. 6 (2004) 724-728.

[100] B.S. Qin, Z.H. Liu, G.L. Ding, Y.L. Duan, C.J. Zhang, G.L. Cui, Electrochim. Acta 141 (2014) 167-172

[101] M.H. Ryou, G.B. Han, Y.M. Lee, J.N. Lee, D.J. Lee, Y.O. Yoon, J.K. Park, Electrochim. Acta 55 (2010) 2073-2077.

[102] Y. Wu, Z. Wen, H. Feng, J. Li, Small 8 (2012) 858-862.

[103] H. Tsunekawa, S. Tanimoto, R. Marubayashi, M. Fujita, K. Kifune, M. Sano, J. Electrochem. Soc. 149 (2002) A1326-A1331.

[104] X. Cui, H. Zhang, S. Li, Y. Zhao, L. Mao, W. Zhao, Y. Li, X. Ye, J. Power Sources 240 (2013) 476-485.

[105] H. Saruwatari, T. Kuboki, T. Kishi, S. Mikoshiba, N. Takami, J. Power Sources 195 (2010) 1495-1499.

[106] S.D. Arno, S. Lucas, A. Shariati, C.J. Peters, J. Solution Chem. 41 (2012) 2173-2185.

[107] G.B. Appetecchi, M. Montanino, A. Balducci, S.F. Lux, M. Winter, S. Passerini, J. Power Sources 192 (2012) 599-605.

[108] H. Wang, N. Imanishi, A. Hirano, Y. Takeda, O. Yamamoto, J. Power Sources 219 (2012) 22-28

[109] C. Gerbaldi, J.R. Nair, S. Ferrari, A. Chiappone, G. Meligrana, S. Zanarini, P. Mustarelli, N. Penazzi, R. Bongiovanni, J. Mater. Sci. 423 (2012) 459-467.

[110] L. Liu, P. Yang, L. Li, Y. Cui, M. An, Electrochim. Acta 85 (2012) 49-56.

[111] C. Täubert, M. Fleischhammer, M. Wohlfahrt-Mehrens, U. Wietelmann, T. Buhrmester, J. Electrochem. Soc. 157 (2010) A721-A728.

[112] S. Ha, J. Han, Y. Song, M. Chun, S. Han, W. Shin, N. Choi, Electrochim. Acta 104 (2013) 170-177.

[113] N.P. Pieczonka, L. Yang, M.P. Balogh, B.R. Powell, K. Chemelewski, A. Manthiram, S.A. Krachkovskiy, G.R. Goward, M. Liu, J.H. Kim, J. Phys. Chem. C 117 (2013) 22603-22612.

[114] D.T. Shieh, P.H. Hsieh, M.H. Yang, J. Power Sources 174 (2007) 663-667.

[115] Y. Song, J. Han, S. Park, K.T. Lee, N. Choi, J. Mater. Chem. A 2 (2014) 9506-9513.

[116] V.Aravindan, Y.L. Cheah, W.C. Ling, S. Madhavi, J. Electrochem. Soc. 159(2012) A1435-A1439.

[117] S. Dalavi, M. Xu, B. Knight, B.L. Lucht, Electrochem. Solid-State Lett. 15 (2011) A28-A31.

[118] S.Y. Li, Y.Y. Zhao, W. Zhao, X.L. Cui, Key Eng. Mater. (2012) 156-159, http://dx.doi.org/10.4028/www.scientific.net/KEM.519.15

[119] M. Xu, N. Tsiouvaras, A. Garsuch, H.A. Gasteiger, B.L. Lucht, J. Phys. Chem. C 118 (2014) 7363-7368.

[120] B. Scrosati, F. Croce, S. Panero, J. Power Sources 100 (2001) 93-100.

[121] F.B. Dias, L. Plomp, J.B. Veldhuis, J. Power Sources 88 (2000) 169-191.

[122] Y.V. Baskakova, O.N. Efimov, Russ. Chem. Rev. 81 (2012) 367-380.

[123] P. Zhang, L. Li, D. He, Y. Wu, S. Makoto, Acta Polym. Sin. (2011) 125-131.

[124] N.A.A. Rossi, R. West, Polym. Int. 58 (2009) 267-272.

[125] A. Manuel Stephan, Eur. Polym. J. 42 (2006) 21-42.

[126] B. Scrosati, DTIC Document, 2007.

[127] F.M. Gray, Royal Society of Chemistry, Cambridge, UK, 1997.

[128] F.M. Gray, M. Armand, in: T. Osaka, M. Datta (Eds.), Energy Storage System for Electronics, Gordon and Breach Science Publications, 2000.

[129] N.A.A. Rossi, Z. Zhang, Q. Wang, K. Amine, R. West, Polym. Prepr. (Am. Chem. Soc., Div. Polym. Chem.) 46 (2005) 723-724.

[130] O. Bohnke, C. Bohnke, J.L. Fourquet, Solid State Ionics 91 (1996) 21-31.

[131] J.M. Lu, F. Yan, J. Texter, Prog. Polym. Sci. 34 (2009) 431-448.

[132] J. Reiter, R. Dominko, M. Nádherná, I. Jakubec, J. Power Sources 189 (2009) $133-138$.

[133] A. Ghosh, C. Wang, P. Kofinas, J. Electrochem. Soc. 157 (2010) A846-A849.

[134] U.Wietlemann, J.C. Panitz, 21st International Seminar \& Exhibition on Primary and Secondary Batteries, Ft. Lauderdale, Florida, March 08-11, (6), 118, 2004.

[135] T.R. Jow, C. Xu, S.S. Zhang, US7820323 (2006).

[136] Y. Sasaki, S. Sekiya, M. Handa, K. Usami, J. Power Sources 79 (1999) 91-96.

[137] Z. Xue, C. Chen, Electrochim. Acta 49 (2004) 5167-5175.

[138] Y. Sasaki, M. Handa, K. Kurashima, T. Tonuma, K. Usami, J. Electrochem. Soc. 148 (2001) A999-A1003.

[139] X. Li, Z. Xue, J. Zhao, C. Chen, J. Power Sources 235 (2013) 274-279.

[140] Z.M. Xue, J. Ding, W. Zhou, C.H. Chen, Electrochim. Acta 55 (2010) 3838-3844.

[141] M. Handa, M. Suzuki, J. Suzuki, H. Kanematsu, Y. Sasaki, Electrochem. SolidState Lett. 2 (1999) 60-62.

[142] M. Wuhr, US5660947 (1997). 
[143] Z. Xue, J. Zhao, J. Ding, C. Chen, J. Power Sources 195 (2010) 853-856.

[144] R. Dietz, U. Wietelmann, U. Lischka, US20100143806 (2010).

[145] H.S. Lee, X.Q. Yang, C.L. Xiang, J. McBreen, L.S. Choi, J. Electrochem. Soc. 145 (1998) 2813-2818.

[146] C.C. Chang, T.K. Chen, L.J. Her, G.T.K. Fey, J. Electrochem. Soc. 156 (2009) A828-A832.

[147] C.C. Chang, T.K. Chen, J. Power Sources 193 (2009) 834-840.

[148] Z. Chen, K. Amine, J. Electrochem. Soc. 153 (2006) A1221-A1225.

[149] M. Herstedt, M. Stjerndahl, T. Gustafsson, K. Edstrom, Electrochem. Commun 5 (2003) 467-472

[150] K. Xu, Chem. Rev. 114 (2014) 11503-11618.

[151] Y.S. Zhu, X.J. Wang, Y.Y. Hou, X.W. Gao, L.L. Liu, Y.P. Wu, M. Shimizu, Electrochim. Acta 87 (2013) 113-118.

[152] S.S. Zhang. C.A. Angell, J. Electrochem. Soc. 143 (1996) 4047-4053.

[153] S. Ganapathiappan, K. Chen, D.F. Shriver, Macromolecules 21 (1988) 2299-2301.

[154] H.R. Allcock, D.T. Welna, A.E. Maher, Solid State Ionics 177 (2006) 741-747.

[155] D.P. Siska, D.F. Shriver, Chem. Mater. 13 (2001) 4698-4700.

[156] Y. Matsuda, M. Morita, H. Tsutsumi, Polym. Adv. Technol. 4 (1993) 209-214.

[157] Z. Florjańczyk, W. Bzducha, N. Langwald, J.R. Dygas, F. Krok, B. Misztal-Faraj, Electrochim. Acta 45 (2000) 3563-3571.

[158] S. Feng, D. Shi, F. Liu, L. Zheng, J. Nie, W. Feng, X. Huang, M. Armand, Z. Zhou, Electrochim. Acta 93 (2013) 254-263.

[159] R. Meziane, J.P. Bonnet, M. Courty, K. Djellab, M. Armand, Electrochim. Acta 57 (2011) 14-19.
[160] R. Bouchet, S. Maria, R. Meziane, A. Aboulaich, L. Lienafa, J.P. Bonnet, T.N.T. Phan, D. Bertin, D. Gigmes, D. Devaux, R. Denoyel, M. Armand, Nat. Mater. 12 (2013) 452-457.

[161] X. Wang, Z. Liu, C. Zhang, Q. Kong, J. Yao, P. Han, W. Jiang, H. Xu, G. Cui, Electrochim. Acta 92 (2013) 132-138.

[162] X. Wang, Z. Liu, Q. Kong, W. Jiang, J. Yao, C. Zhang, G. Cui, Solid State Ionics 262 (2014) 747-753.

[163] Y. Zhu, S. Xiao, Y. Shi, Y. Yang, Y. Wu, J. Mater. Chem. A 1 (2013) 7790-7797.

[164] Y. Zhang, G. Xu, Y. Sun, B. Han, Z. Chen, R. Rohan, H. Cheng, RSC Adv. 3 (2013) 14934-14937.

[165] Y. Zhu, S. Xiao, Y. Shi, Y. Yang, Y. Hou, Y. Wu, Adv. Eng. Mater. 4 (2014), http://dx.doi.org/10.1002/aenm.201300647.

[166] W. Xu, M.D. Williams, C.A. Angell, Chem. Mater. 13 (2002) 401-409.

[167] W. Xu, C.A. Angell, Solid State Ionics 147 (2002) 295-301.

[168] W. Xu, J.P. Belieres, C.A. Angell, Chem. Mater. 13 (2001) 575-580.

[169] Y.S. Zhu, X.W. Gao, X.J. Wang, Y.Y. Hou, L.L. Liu, Y.P. Wu, Electrochem. Commun. 22 (2012) 29-32.

[170] S. Hyoung Oh, T. Yim, E. Pomerantseva, L.F. Nazar, Electrochem. Solid-State Lett. 14 (2011) A185-A188.

[171] R. Younesi, M. Hahlin, K. Edstrom, ACS Appl. Mat. Interfaces 5 (2013) 1333-1341.

[172] E. Nasybulin, W. Xu, M.H. Engelhard, Z. Nie, S.D. Burton, L. Cosimbescu, M.E. Gross, J.G. Zhang, J. Phys. Chem. C 117 (2013) 2635-2645.

[173] S.S. Zhang, J. Power Sources 231 (2013) 153-162.

[174] C. Ge, L. Wang, L. Xue, Z. Wu, H. Li, Z. Gong, X. Zhang, J. Power Sources 248 (2014) 77-82. 